\title{
On the relations between aromaticity and substituent effect
}

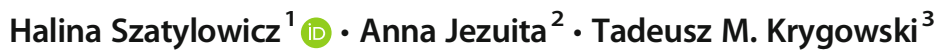

Received: 11 March 2019 / Accepted: 21 May 2019 / Published online: 12 July 2019

(C) The Author(s) 2019

\begin{abstract}
Aromaticity/aromatic and substituent/substituent effects belong to the most commonly used terms in organic chemistry and related fields. The quantitative description of aromaticity is based on energetic, geometric (e.g., HOMA), magnetic (e.g., NICS) and reactivity criteria, as well as the properties of the electronic structure (e.g., FLU). The substituent effect can be described using either traditional Hammett-type substituent constants or characteristics based on quantum-chemistry. For this purpose, the energies of properly designed homodesmotic reactions and electron density distribution are used. In the first case, a descriptor named SESE (energy stabilizing the substituent effect) is obtained, while in the second case cSAR (charge of the substituent active region), which is the sum of the charge of the ipso carbon atom and the charge of the substituent. The use of the above-mentioned characteristics of aromaticity and the substituent effect allows revealing the relationship between them for mono-, di-, and polysubstituted $\pi$-electron systems, including substituted heterocyclic rings as well as quasi-aromatic ones. It has been shown that the less aromatic the system, the stronger the substituent influence on its $\pi$-electron structure. In all cases, when the substituent changes number of $\pi$-electrons in the ring in the direction of $4 \mathrm{~N}+2$, its aromaticity increases. Intramolecular charge transfer (a resonance effect) is privileged in cases where the number of bonds between the electron-attracting and electron-donating atoms is even. Quasi-aromatic rings, when attached to a truly aromatic hydrocarbon, simulate well the "original" aromatic rings, alike the benzene. For larger systems, a long-distance substituent effect has been found.
\end{abstract}

Keywords Molecular modeling · Substituent effect · Electronic structure $\cdot$ Substituent effect stabilization energy $\cdot$ Charge of the substituent active region

\section{Introduction}

Aromaticity and substituent effects are among the most important and useful terms in organic chemistry and related fields. Taking into account the last decade (2008-2017),

Dedicated to Professor Zbigniew Galus of the Department of Chemistry of the Warsaw University our friend and outstanding physical chemist on the occasion of his 85th anniversary.

Halina Szatylowicz

halina@ch.pw.edu.pl

1 Faculty of Chemistry, Warsaw University of Technology, Noakowskiego 3, 00-664 Warsaw, Poland

2 Faculty of Chemistry, Opole University, Oleska 48, 45-052 Opole, Poland

3 Department of Chemistry, Warsaw University, Pasteura 1, 02-093 Warsaw, Poland entries: aromatic/aromaticity, substituent(s) and substituent effect(s) appear in title, abstract or key words on average 35, 12, and 4 times per day, respectively [1]. Both aromaticity and substituent effect concepts are an old story, but still alive, fascinating, and inspiring.

For the first time, the chemical idea of aromaticity appeared as a structural concept: Kekule addressed the term to compounds containing the benzene ring [2]. A year later, Erlenmayer [3] named as aromatic the compounds having similar properties as benzene derivatives. The most important aspects of the development of the concept of aromaticity are presented in Table 2 of the review paper by Schleyer and coworkers [4].

There has been some kind of dichotomy since then: how to understand the aromatic character, using a chemical structure or chemical properties? To date, most of the works on aromaticity have been devoted to relationships between the structure and the properties of so-called aromatic compounds. It was found very early that the most significant chemical properties 
that differentiate aromatic compounds from their unsaturated analogs are that "they are inclined to substitution and disinclined to addition reactions and are thermally stable" as Robinson concluded [5].

The first quantitative approach to determine aromaticity is based on the concept of resonance energy (RE) [6] defined as the difference between the energy of a given molecule and the energy of its reference model, the "unsaturated" analog. It was widely used to $\pi$-electron compounds, including those that contain heteroatoms such as nitrogen, sulfur, and oxygen [7]. RE was also associated with delocalization energy (DE) defined as the calculated additional bonding energy which "results from delocalization of electrons originally constrained to isolated double bonds" [8]. The greater RE/DE values, the more stable is a molecule and higher its aromatic character. The RE concept has undergone many modifications concerning both the models of reference molecules and the level of theory used to estimate energies. RE values can be estimated from experimental thermochemical data $[9,10]$ or by the use of quantum chemistry computation. Dewar et al., using Parr-Pariser-Pople $\pi$-electron method, found that bond energies of acyclic polyenes are additive [11-13] and then the so-called Dewar resonance energy (DRE) was introduced [14]. Based on the same rule of bond energy additivity, Hess and Schaad used the simple Hückel Molecular Orbital (HMO) approach to a large number of $\pi$-electron hydrocarbons [15-17] and hetero $\pi$-electron compounds [18] and a new term was introduced - the Hess-Schaad stabilization energy (HSSE), for review see [19]. The use of resonance energy per $\pi$-electron (REPE) allows to compare the aromaticity of molecules of different sizes. Stabilization energies can be determined using different reference systems, a wide and instructive review by Cyrański presents all these problems in detail [14]. The HMO approach was also applied to quantitative definition of aromaticity, named by an acronym KK. It is based mainly on chemical intuition and defined as "an amount of $\pi$-electron energy that the molecule loses as a result of an addition reaction at positions $r$ and $s$, i.e. when in those positions a change of hybridization state from $\mathrm{sp}^{2}$ to $\mathrm{sp}^{3}$ occurs" [20]. Schematically, the idea of $\mathrm{KK}$ index is presented in Fig. 1.

The higher the KK value, i.e., the greater energy loss due to the addition reaction, the more difficult the molecule is to undergo this reaction, and the more aromatic the molecule is. This definition of aromaticity is evidently related to the old chemical issue that aromatic molecules prefer a substitution reaction rather than an addition reaction [21]. Thanks to this approach, $\pi$-electron systems can be classified as shown in Fig. 2: annulenes with $4 \mathrm{~N}+2$ and $4 \mathrm{~N} \pi$-electrons form two curves, and between them and below there are other cyclic and acyclic $\pi$-electron systems [22]. A similar graph but only for annulenes was presented earlier by Dewar [23] and Figeys [24], for review and generalization see [25].

The first quantitative characteristic of aromaticity based on molecular geometry was introduced by Julg and Francoise [26]. It was defined as a function of the normalized variance of the perimeter bond lengths. The greater deviation from the mean bond length, the less delocalization of the $\pi$-electrons, and the molecule is less aromatic. Next year, the bond lengths were replaced by the HMO bond orders and the difference between the mean bond order and the bond orders of all bonds of a molecule, taken in modulo and normalized, gave a numerical descriptor of aromaticity [27]. In the next step, the average value of bond lengths was replaced by an empiric concept of optimal bond length [28, 29]. Then, differences in the length of bonds, $d_{i}$, in a given molecule from the optimal bond length, $d_{\text {opt }}$, were used as the basis for
Fig. 1 Scheme of the reaction path for substitution and addition in terms of $\pi$-electron energies. Reprinted (adapted) from

Tetrahedron Lett 11:320 (1970)

[20]. Copyright (1970), with permission from Elsevier

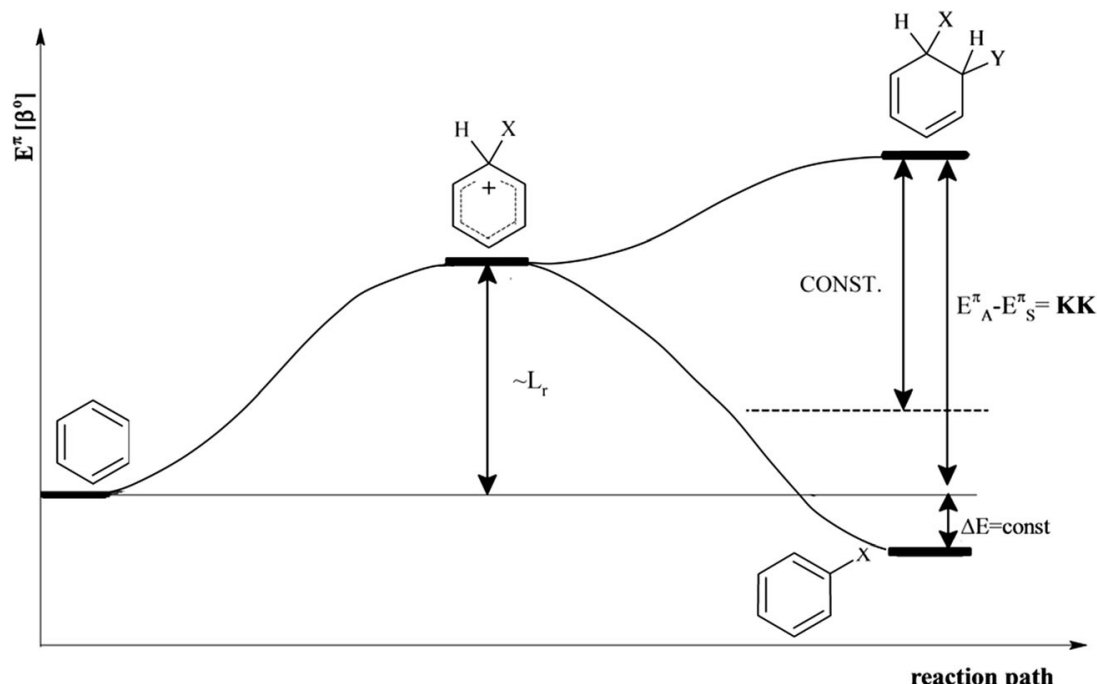

reaction path

A - addition reaction $\quad \mathrm{S}$ - substitution reaction $\quad \mathrm{L}_{\mathrm{r}}$ - loss $\pi$-electron energy 
Fig. 2 Dependence of KK index on the number of $\pi$-electrons in molecules. Reprinted (adapted) from Tetrahedron Lett 11: 1311 (1970) [22]. Copyright (1970), with permission from Elsevier

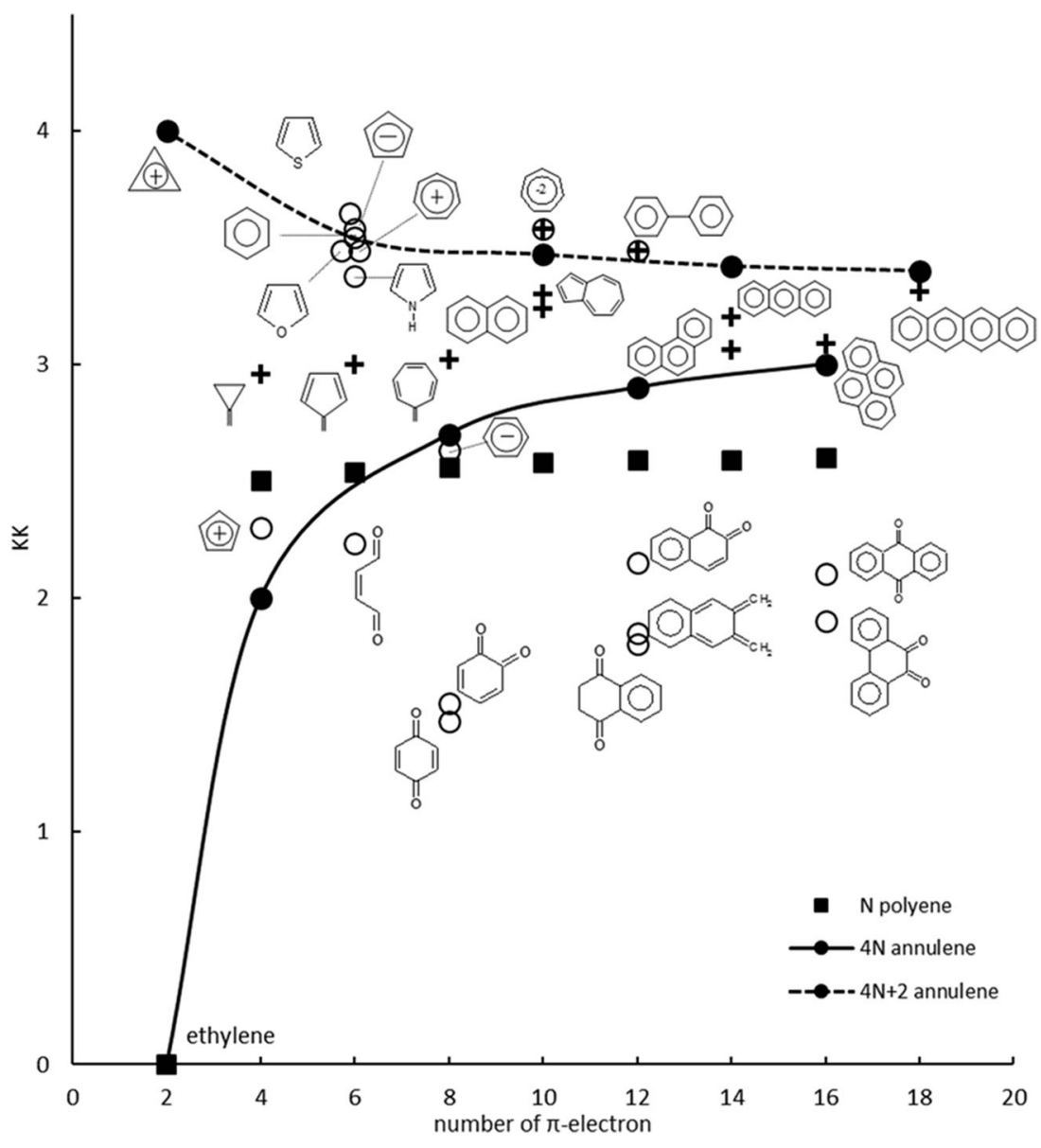

estimating aromaticity index named HOMA (Harmonic Oscillator Model of Aromaticity):

$\mathrm{HOMA}=1-\frac{1}{n} \sum_{i=1}^{n} \alpha\left(d_{o p t}-d_{i}\right)^{2}$

where $n$ is the number of CC bonds taken into a consideration, $\alpha=257.7$ is an empirical normalization constant chosen to give HOMA $=0$ for non-aromatic system and HOMA $=1$ for a system where all bonds are equal to $d$ opt $=1.388 \AA$, and $d_{\mathrm{i}}$ are the bond lengths.

For $\pi$-electron systems with heteroatoms the parameters: $d_{\text {opt }}$ and $\alpha$, are given in collection of papers [29-34]. An important advantage of the HOMA approach is that it can be used for estimation of $\pi$-electron delocalization of any $\pi$ electron fragment of a molecule. The approach has been modified many times [34-36] but the basic idea has not been changed. A few years later, Bird introduced aromaticity index $\mathrm{I}_{6}$ for six-membered rings [37] and $\mathrm{I}_{5}$ for five-membered ones [38] using the bond orders calculated directly from bond lengths via the formula suggested by Gordy [39].

Some help in understanding the aromatic character can come from the harmonic oscillator stabilization energy (HOSE) [40, 41]. This approach is related to the well-known way in organic chemistry of presenting the chemical properties of molecules using their resonance structures [42]. The HOSE is based on estimation of the stabilization energy and the contribution of particular Kekule' (canonical) structures, obtained from experimental bond lengths, in the description of a $\pi$-electron system. The physical meaning of $\mathrm{HOSE}_{\mathrm{i}}$ can be interpreted as follows: it is energy by which the real molecule is more stable than its $i^{\text {th }}$ Kekule' structure. Among the many applications of the HOSE model, two of them show their advantages. The obtained HOSE values [41] were found to be in a good correlation with the RE values obtained by Hess and Schaad for alternant hydrocarbons [15] and non-alternant species [17], with correlation coefficients, $c c, 0.991$ (for $n=22$ data points) and 0.937 (for $n=12$ ), respectively. There was also a very good correlation between HOSE contributions [41] of the resonance structures and those proposed by Randic [43] ( $c c=0.985$ for $n=65$ data points). Recently, it has been found that HOSE contributions of resonance structures correlate very well with canonical structures estimated using a topological approach, $c c=0.997$ for 150 data points [44]. A detailed overview of the geometrybased aromaticity indices can be seen in the review [45].

Another approach to determine aromaticity has come from magnetic studies of $\pi$-electron systems. One of the first descriptors of this type is the diamagnetic susceptibility 
exaltation. Already in 1968, it was proposed as a criterion of aromaticity [46], since it was accepted as a documentation of the presence of $\pi$-electron delocalization in a molecule [47, 48]. It is important to mention that magnetic susceptibility is a property of a whole molecule and can be obtained both experimentally and by quantum chemistry computations. Some kind of revolution was introduction in 1996 by Schleyer of the concept of nucleus independent chemical shift (NICS) [49]. It was defined as the negative value of the absolute shielding calculated in the geometric center of the ring system. Now it is also calculated at other points inside [50] or around molecules [4]. Due to many possibilities of the point and way of NICS estimation, Schleyer recommended a component corresponding to the principal axis perpendicular to the ring plane, $\mathrm{NICS}_{\mathrm{zz}}$, as the preferred measure for characterizing the $\pi$ system [51]. Another possibility is to estimate the NICS value $1 \AA$ above the molecular plane, named NICS(1) [4]. It should be mentioned that all NICS values describe only local aromaticity, i.e., of a particular ring, moreover, they depend not only on the size of the ring but also on the neighboring parts of the ring in question.

In recent decades, there have been characteristics of aromaticity based clearly on electron structure and electron delocalization. For this purpose, electron structure descriptors based on AIM theory [52-54] were used: charges, Laplacian, energy, and its components such as kinetic and potential energies, estimated at the bond or ring critical points $[55,56]$.

Other approaches based on the electronic structure are associated with characteristics of electron delocalization. In the case of six-member rings, a delocalization index for atoms in para positions was defined, PDI [57], whereas for all atoms in the ring as well as any $\pi$-electron fragments - a multicenter bond index, MCI [58]. In 2005, Sola et al. [59] introduced the aromatic fluctuation index, FLU, that describes the fluctuation of electronic charge between adjacent atoms in a given ring. It has been documented that above-mentioned indices are well correlated with HOMA and NICS for benzenoids as well as non-benzenoid hydrocarbons, and even nitrogen analogs and some unsaturated cyclic systems. For review see [60].

In front of so many possible criteria of aromaticity an important question arises: how far so different approaches lead to equivalent conclusions? This problem was the subject of many papers [61-65]. The answer, at least to the extent to which the problem in question relates to the traditional definition of aromaticity, was presented by Cyrański et al. [66]. In general, the overall trend is broadly met and there are correlations between the aromaticity indexes, but in many specific situations, they may lead to inconsistent results. However, the use of any of the well-accepted aromaticity descriptors for structurally similar molecular systems should lead to reliable conclusions [67]. This condition is met for substituted derivatives of a given molecule.
One more descriptor of electron structure of aromatic compounds may come from the pEDA/sEDA approach [68]. The pEDA and SEDA descriptors are defined as populations of the $\pi$ - and sigma orbital electrons, respectively, in a given planar molecule or its planar part.

Recently, an approach based on quantum chemistry has been introduced - named as the electron density of delocalized bonds, EDDB [69], and successfully applied as an aromaticity criterion [70] as well as used for description of aromaticity of acenes [71]. The EDDB method revealed that the local aromaticity of a particular ring in a polycyclic benzenoid hydrocarbon may be significantly affected by longrange exchange corrections in the description of electron delocalization [72].

Substituent effect (SE) is another term in the title which requires a substantial comment. It is well recognized that benzene is a toxic and dangerous carcinogen, its substituted derivative - benzoic acid - is applied in the preparation of commonly used preservatives, in a form of its sodium or calcium salts. Subsequent substitution by acetylic group leads to a drug, well known under the name of aspirin [73]. This type of qualitative picture presents a broad spectrum of changes in chemical/physicochemical and even biochemical properties. However, still, a significant problem exists: how to describe the substituent effect quantitatively. The first quantitative approach in describing the substituent effect was proposed by Louis Plack Hammett [74, 75]. He introduced, as the quantitative characteristic of the substituent effect, the substituent constant termed $\sigma$, defined by Eq. (2):

$\sigma(\mathrm{X})=\lg K(\mathrm{X})-\lg K(\mathrm{H})$

where $K(\mathrm{X})$ and $K(\mathrm{H})$ are equilibrium constants for substituted and unsubstituted benzoic acids in water under normal conditions.

For chemical processes, rate, or equilibrium constants $(k$ or $K$, respectively), the use of the substituent constants leads to the Hammett equation, Eq. (3):

$\lg (K(\mathrm{X})$ or $k(\mathrm{X}))=\rho \sigma(\mathrm{X})_{\mathrm{p}, \mathrm{m}}+$ const

where $\rho$ is the so-called reaction constant and describes sensitivity of the process to the impact of the substituent X.

The value of const in Eq. (3) should be close to the $\lg K(\mathrm{H})$ or $\lg k(\mathrm{H})$, this is for unsubstituted system. In principle, the Hammett equation is a typical similarity model [76], changes in physicochemical properties $\mathrm{P}(\mathrm{X})$ follow the general equation:

$\mathrm{P}(\mathrm{X})=\rho \sigma(\mathrm{X})_{\mathrm{p}, \mathrm{m}}+$ const

The above equations postulate that changes in various chemical/physicochemical properties observed in the "reaction site" $\mathrm{Y}$ in X-R-Y systems depend in a similar way on substituents $\mathrm{X}$ as the acidity of $m$ - and $p$-substituted 
benzoic acids. The Hammett equation or its modifications have found countless applications. It has been widely documented that substituent constants may well serve to describe impact of the substituent on most of the physicochemical and even biochemical properties of molecules [77-84]. Already in the first three decades, since the original idea was introduced, over 20 different modifications of the original Hammett substituent constants appeared [85]. They have been designated for various specific types of intramolecular interactions. However, in general, they have caused some disappointment in understanding how these empirical modeling of substituent effect can really work. Thus, some clarification of the topic is important for the advantageous use of the terms of the substituent effect and substituent constants.

Substituent constants have been used to parametrize the HMO-based approach Then, parameters for resonance and Coulomb integrals in the HMO theory (for review see Streitwieser [86]) were related to the Hammett substituent constants $\sigma$, leading to the concept of an Effective Inductive Parameter (EIP) [87]. The application of the HMO EIP model allowed an interpretation of polarographic E1/2 potentials of dichloro-anthraquinone derivatives for first and second steps of electroreduction [27], substituent effects on polarographic properties of some aromatic nitro- and azo-compounds [88] and on PMR chemical shifts of monosubstituted thiophene derivatives [89].

A very interesting description of electronic properties of the substituent results from the statistical analysis of the geometry patterns of monosubstituted benzene rings [90, 91]. The benzene ring deformations are associated with the old concept of group electronegativity $[92,93]$ and with the one recently modified by the Domenicano research group [94, 95].

The dynamic development of quantum chemistry methods and computer-aided applications [96] has created a very convenient atmosphere for research in the field of SE. To define one of the first SE descriptors based on quantum chemistry, a homodesmotic reaction $[97,98]$ was used:

$\mathrm{X}-\mathrm{R}-\mathrm{Y}+\mathrm{R} \rightarrow \mathrm{X}-\mathrm{R}+\mathrm{R}-\mathrm{Y}$.

Then, the energy of this reaction, according to Eq. (5):

$$
\mathrm{SESE}=\mathrm{E}(\mathrm{R}-\mathrm{X})+\mathrm{E}(\mathrm{R}-\mathrm{Y})-[\mathrm{E}(\mathrm{X}-\mathrm{R}-\mathrm{Y})+\mathrm{E}(\mathrm{R})]
$$

describes the overall energy of the process and was named Substituent Effect Stabilization Energy (SESE). Most often, its values are well correlated with the Hammett constants [99]. When the SESE value is positive, it means that the intramolecular interactions between the substituents $\mathrm{X}$ and $\mathrm{Y}$ in X-RY stabilize the system.

Another successful approach based on quantum chemistry refers to the application of the molecular electrostatic potential (MESP) topography, documented for monosubstituted benzene derivatives by a good correlation with SC's [100]. The use of

MESP on the ring carbon atoms or in the atoms of the reaction site also revealed their good correlations with SC's [101-103]. In addition, the MESP approach allowed to appraise the through bond and through space interactions [104]. Molecular electrostatic potential has also been used for the quantitative assessment of the inductive effect [105] and finally to the classification of the substituent effect [106].

The first electronic interpretation of the substituent effect was proposed by Hammett [75]. However, the direct application of the substituents atomic charges, $q(X)$, does not correlate with the Hammett substituent constants. Such correlation works well when instead $\mathrm{q}(\mathrm{X})$ the charge of the substituent active region approach, abbreviated cSAR(X), introduced by Sadlej-Sosnowska [107, 108], is applied. It is defined as a sum of atomic charges of all atoms of the substituent $\mathrm{X}$ and the ipso carbon atom:

$\operatorname{cSAR}(\mathrm{X})=\mathrm{q}(\mathrm{X})+\mathrm{q}\left(\mathrm{C}_{\text {ipso }}\right)$

In addition, in the disubstituted benzene derivatives X-Ph$\mathrm{Y}$, the cSAR values allowed to estimate the magnitude of the charge transferred from $\mathrm{X}$ to $\mathrm{Y}$, or vice versa [109].

The success of $\operatorname{cSAR}(X)$ compared to $\mathrm{q}(\mathrm{X})$ is due to the fact that $\mathrm{CC}$ bonds cut for the $\operatorname{cSAR}(\mathrm{X})$ approach are very weakly polar in opposition to C-X bonds. The latter can be very polar and therefore sensitive to the method of atomic charge assessments, as shown in Scheme 1.

As mentioned above, in contrast to the atomic charges of the substituent $q(X)$, the $\operatorname{cSAR}(X)$ values correlate well with SC's [110], moreover, independently of the type of atomic charge assessments (Mulliken [111], AIM [112], Voronoy [113], Hirshfeld [114] and NBO [115]). This has been documented for 12 parasubstituted derivatives of nitrobenzene. Figure 3 presents linear regressions between $\operatorname{cSAR}(\mathrm{X})$ values calculated by the use of different methods of atomic charge assessment. Even if the correlation for AIM data is weaker, however, when the cSAR $\left(\mathrm{NO}_{2}\right)$ values are estimated using these different methods, all mutual correlations are excellent, as presented in Fig. 4.

Recent studies on disubstituted benzene and cyclohexa1,3-diene derivatives have provided support for use of quantum chemistry-based substituent characteristics. The substituent effect estimated by $\operatorname{cSAR}(\mathrm{X})$ and SESE exhibited equivalent effectiveness as the traditional substituent constants. Molecular systems of the series X-R-Y have been investigated for 16 substituents and seven "reaction

a)

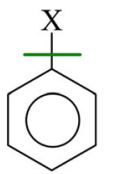

b)

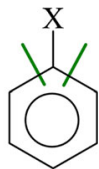

Scheme 1 Graphical presentation of $\mathrm{q}(\mathrm{X})$ (a) and $\operatorname{cSAR}(\mathrm{X})(\mathbf{b})$ definitions. 


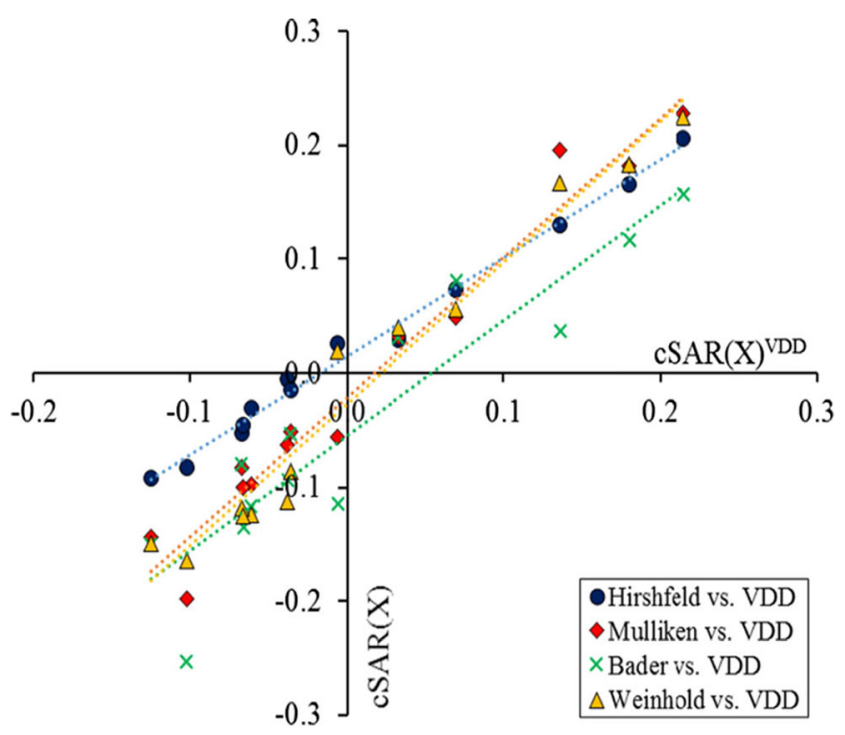

Fig. 3 Linear correlations between $\operatorname{cSAR}(\mathrm{X})$ values calculated by VDD method and data from Hirshfeld, Mulliken, Bader, and Weinhold approaches for $p$-nitrobenzene $\mathrm{X}$ derivatives with $\mathrm{X}=\mathrm{NO}_{2}, \mathrm{CN}, \mathrm{CHO}$, COOMe, $\mathrm{COMe}, \mathrm{Cl}, \mathrm{H}, \mathrm{Me}, \mathrm{OMe}, \mathrm{NH}_{2}$ and $\mathrm{NHMe}(c c=0.996,0.981$, 0.923 and 0.982 , respectively. Reused from [110], this work is licensed under the Creative Commons Attribution 4.0 International License (http:// creativecommons.org/licenses/by/4.0/)

sites", $\mathrm{Y}=\mathrm{NO}_{2}$ [116, 117], $\mathrm{OH}$ [118], $\mathrm{COOH}$ [119], $\mathrm{NH}_{2}$ $[120,121]$ as well anionic $\mathrm{COO}^{-}[119]$ and $\mathrm{O}^{-}[118]$ moieties, with substituents in three and four positions of $\mathrm{R}=$ benzene or cyclohexa-1,3-diene. In addition, the use of both traditional and quantum chemistry-based descriptors of SE allows us to answer the question of how far the substituent effect in disubstituted cyclohexa-1,3-diene derivatives differ from those in bicyclo[2,2,2]octane and benzene [122]. The use of quantum chemistry-based

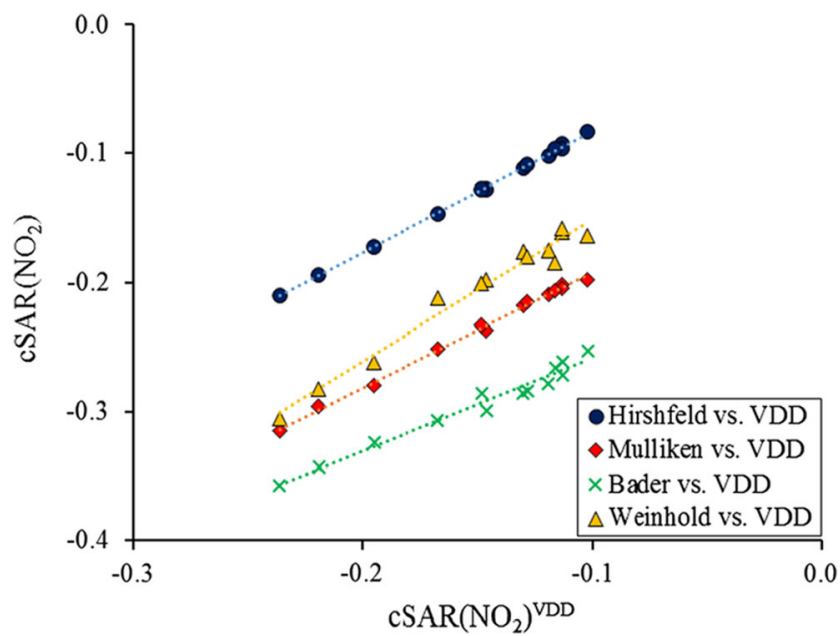

Fig. 4 Correlation between cSAR $\left(\mathrm{NO}_{2}\right)$ calculated from VDD charges and data from Hirshfeld, Mulliken, Bader and Weinhold methods for $\mathrm{p}$ nitrobenzene $\mathrm{X}$ derivatives with $\mathrm{X}=\mathrm{NO}_{2}, \mathrm{CN}, \mathrm{CHO}, \mathrm{COOMe}, \mathrm{COMe}$, $\mathrm{Cl}, \mathrm{H}, \mathrm{Me}, \mathrm{OMe}, \mathrm{NH}_{2}$ and $\mathrm{NHMe}(c c=0.999,0.998,0.986$ and 0.986, respectively). Reused from [110], this work is licensed under the Creative Commons Attribution 4.0 International License (http://creativecommons. org/licenses/by/4.0/) descriptors has allowed to study dependence of the solvent on SE [123] and also provided a physical interpretation of the inductive and resonance effects [124].

There are two types of studies related to the substituent effect. Either they are realized by some specific exchange of one substituent by another or they are devoted to research on changes of some physicochemical or biochemical properties, taking into account a set of substituents, so-called "reaction series." In the first case, the influence of the substituent change on some chemical, physicochemical, or biochemical properties is examined, while in the second - a certain generalization for the collected data is looked for. In this report, we will review the second type of the approach.

\section{Classification of the substituent effect}

There are a few possible classifications of how the substituent effect can be taken into account. The most general model is presented in Scheme 2. The most frequently used type of interaction is named as classical or traditional SE, where properties of the "reaction site" $\mathrm{Y}$ (the fixed group in the series) in the disubstituted X$\mathrm{R}-\mathrm{Y}$ system are related to properties of the substituent. The other type of SE is when the properties of the substituent $\mathrm{X}$ are related to the nature of the "reaction site" Y. These interactions are known as the reverse SE [110]. One more aspect of SE is observed when properties of the $\mathrm{R}$ transmitting moiety are a subject of the influence of the substituent $\mathrm{X}$ ( or of both, $\mathrm{X}$ and $\mathrm{Y}$ ), and finally when various properties of the $\mathrm{Y}$ fragments are mutually interrelated.

Another classification can be made when the SE is considered for mono-, di-, tri-, and multi-substituted species. The di- and multi-substituted systems are much more complex and problems with additivity or non-additivity of SE appear $[125,126]$. Hence, related papers are rarely

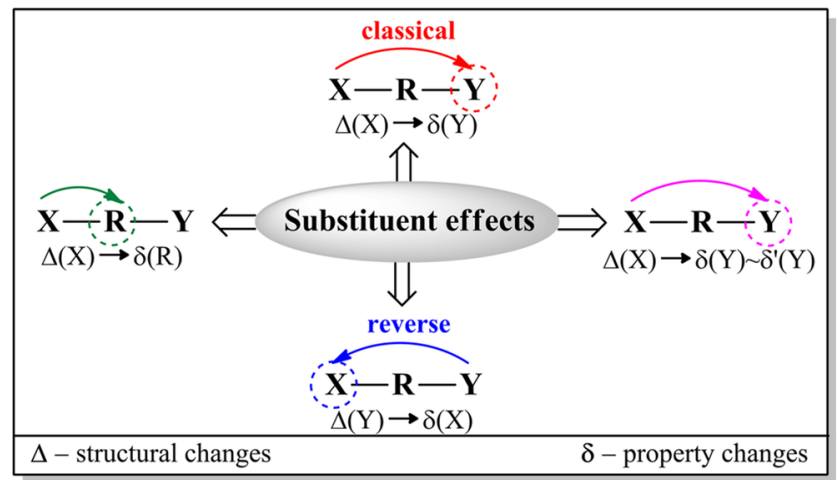

Scheme 2 Model approach to the substituent effect. Graphical abstract reprinted from Phys Chem Chem Phys 18:11711-11721 (2016) [120] with permission from the PCCP Owner Societies. 
a)<smiles>[X]C1=CC=CCC1</smiles><smiles>[X]C1=CCCC=C1</smiles>

c)<smiles>[X]c1ccccc1</smiles>

Scheme 3 Substituted derivatives of cyclohexa-1,3-diene (CHD): 1-XCHD and 2-X-CHD (a) and benzene: $\mathrm{X}-\mathrm{Ph}(\mathbf{b}) ; \mathrm{X}=\mathrm{NMe}_{2}, \mathrm{NH}_{2}, \mathrm{OH}$, $\mathrm{OMe}, \mathrm{CH}_{3}, \mathrm{H}, \mathrm{F}, \mathrm{Cl}, \mathrm{CF}_{3}, \mathrm{CN}, \mathrm{CHO}, \mathrm{COMe}, \mathrm{CONH}_{2}, \mathrm{COOH}, \mathrm{NO}_{2}$, $\mathrm{NO}$

found in literature. Finally, some types of SE may be considered for polycyclic systems, where sometimes no simple rules work.

It should be emphasized that the use of SE descriptors based on quantum chemistry enables the quantitative characterization of the reverse SE, which describes how much a given substituent can change its electron-donating/-attracting properties in dependence on the place and the type of the molecular system to which it is attached. This type of effects was already observed by Hammett [75] showing that the substituent constants for nitro group in para- $\mathrm{NO}_{2}$-phenol and in para- $\mathrm{NO}_{2}$-benzoic acids differ significantly: 1.27 and 0.78 , respectively. In addition, the quantum chemistry-based SE descriptors, such as $\operatorname{cSAR}(\mathrm{X})$ or SESE, allow to estimate an electron-donating/-attracting ability of any substituent and in almost all possible cases (systems).

\section{Monosubstituted $\pi$-electron systems}

The first paper on the quantitative dependence of aromaticity on SE was made in 1970 [127]. Aromaticity was characterized by index $D_{q}$, defined as a modulo of the normalized sum of differences between the HMO calculated averaged atomic $\pi$ electron charges and the charge in the position $\mathrm{r}$, respectively. Therefore, $\mathrm{D}_{\mathrm{q}}$ is a measure of SE on $\pi$-electron structure of benzene ring or, in other words, on a differentiation of atomic charges in the ring. When $\mathrm{D}_{\mathrm{q}}$ values are plotted against the modulo of the substituent constants $\sigma_{\mathrm{p}}$, then changes in aromaticity due to the impact of the substituent $\mathrm{X}$ are described by the equation:

$\mathrm{D}_{\mathrm{q}}=-0.915\left|\sigma_{\mathrm{p}}\right|+0.084$

with $c c=-0.946$ (for $n=10$ data points).

This means that for a stronger SE, a greater diversity of $\pi$ electron charges in the ring is observed. It can be compared with other studies of SE on aromaticity in mono-substituted benzene derivatives. For 19 systems [128] different descriptors of aromaticity were used, such as: aromatic stabilization energy (ASE) [129], HOMA [29], NICS's [4], and electron delocalization PDI index [57], whereas substituents were characterized by substituent constants. The obtained results revealed that, with exception of ASE, all other indices change to a small extent, indicating high resistance of the $\pi$-electron in benzene ring to the SE [128]. In all cases, the correlation coefficients have affirmed good linear regression. This is somewhat analogous to a well-known tendency of benzenelike systems to preserve their initial $\pi$-electron structure during the reaction course, that leads to aromatic substitution [21]. Therefore, it is not surprising that SE can be observed much better in less aromatic $\pi$-electron systems.

A very symptomatic is comparison of SE on $\pi$-electron delocalization found in monosubstituted cyclohexadiene (olefinic) and benzene (aromatic) systems. Relationships, for 16 substituted derivatives (see Scheme 3), between obtained HOMA values and substituent constants are presented in Figs. 5 and 6, respectively [130]. They show that $\pi$-electron delocalization in olefinic system increases with an increase of the electron-accepting/donating strength of SE described by substituent constants, whereas in the aromatic system, the trend is opposite and less pronounced.

Differences in the impact of SE on the $\pi$-electron delocalization in olefinic and aromatic systems has also been expressed by comparisons of linear regressions of
Fig. 5 Dependence of HOMA on substituent constants, $\sigma_{\mathrm{p}}$, for 1 $\mathrm{X}$-cyclohexa-1,3-dienes. Reprinted from RSC Adv 6: 96528 (2016) [130]. Copyright 2016 with permission from The Royal Society of Chemistry

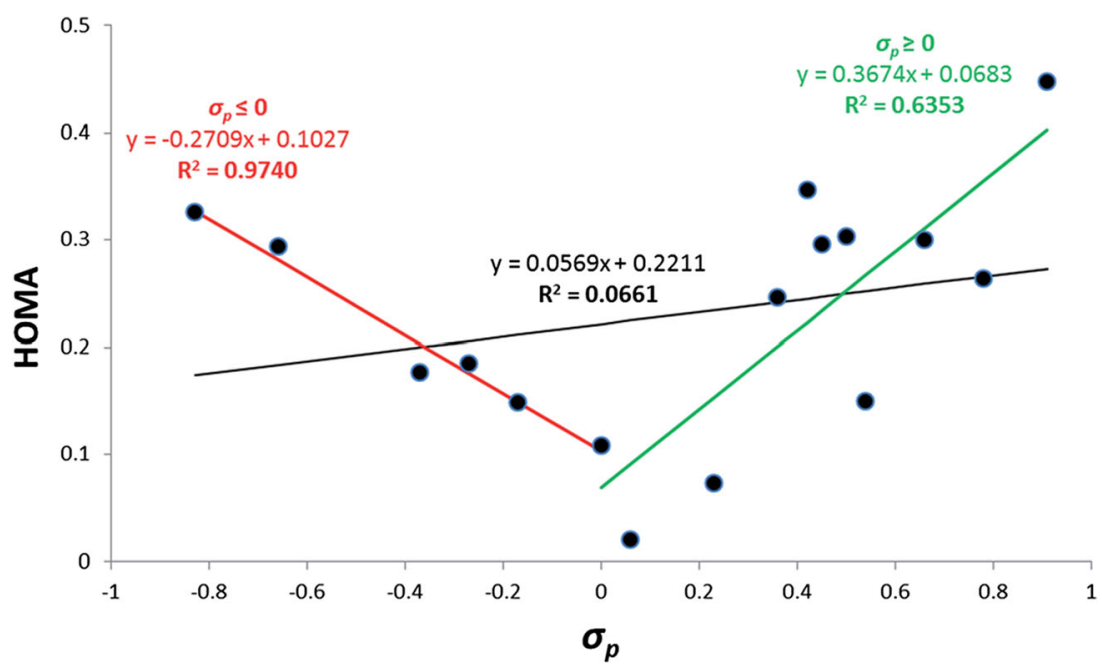


Fig. 6 Dependence of HOMA on substituent constants, $\sigma_{\mathrm{p}}$, for mono-substituted benzene derivatives. Reprinted from RSC Adv 6: 96528 (2016) [130]. Copyright 2016 with permission from The Royal Society of Chemistry

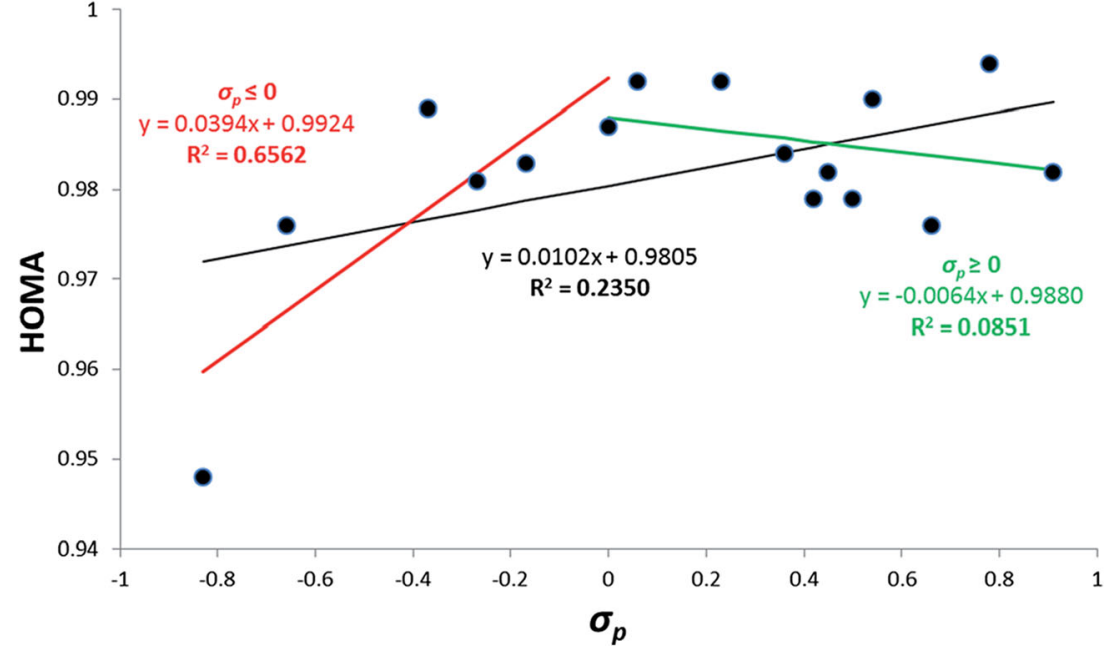

cSAR(X) on substituent constants in 1 and 2 positions in cyclohexadiene and in benzene (see Scheme 3), as presented in Table 1. Similarly, the regressions of $\operatorname{cSAR}(\mathrm{X})$ in 1- and 2-substituted cyclohexadiene CHD) differ from that observed in monosubstituted benzene. It has been shown that the position 1- in CHD is significantly more sensitive to SE than position 2- while the sensitivity of benzene is in between. Undoubtedly, the obtained slopes (Table 1 ) describe ability the $\pi$-electron systems for transmission of the SE.

Pentafulvene and heptafulvene (Scheme 4) are considered as non- or weakly aromatic classical cyclic $\pi$-electron systems. For exocyclic substituted fulvene derivatives changes of aromaticity due to SE were studied by means of the HOMA index, estimated from experimental bond lengths [131]. The HOMA values of pentafulvene derivatives were characterized by a large variability range: between -0.106 for 6-(4-dimethylaminophenyl)fulvene and 0.702 for 6dimethylamino-piperidinofulvene. In addition, the greatest HOMA value, equal to 0.986 , was found for a salt: dicyclopentadienyl calcium, where five $\pi$-electron ring of pentafulvene accepts the sixth electron from calcium atom, changing it into cation. Consequently, this allows the fivemember ring to follow the Hückel rule, promoting it to the ring of type $4 \mathrm{~N}+2$.

A similar conclusion was drawn from the results of a study of ring currents in complexes of pentafulvene with $\mathrm{Li}$ atoms [132]. The wider study [133] carried out for aromaticity (using of NICS, HOMA, pEDA indices) of pentafulvene complexes

Table 1 Regressions of $\operatorname{cSAR}(\mathrm{X})$ on $\sigma$ constant: $\operatorname{cSAR}(\mathrm{X})=a \cdot \sigma+b$ (from ref. [130])

\begin{tabular}{llrl}
\hline Series & \multicolumn{1}{l}{$a$} & \multicolumn{1}{l}{$b$} \\
\hline 1-X-CHD & -0.263 & 0.010 & 0.906 \\
2-X-CHD & -0.222 & -0.057 & 0.862 \\
X-Ph & -0.244 & -0.015 & 0.901 \\
\hline
\end{tabular}

with alkaline metal ( $\mathrm{Li}, \mathrm{Na}, \mathrm{K}, \mathrm{Rb}$, and $\mathrm{Cs}$ ) shown that HOMA for free molecule of pentafulvene was -0.297 and for all salts the values were $\sim 0.560$, revealing a good agreement with other aromaticity descriptors.

Substituent effects on $\pi$-electron delocalization were also investigated for a set of 29 exocyclically substituted fulvene derivatives [134]. Changes of aromatic character were observed in ring currents and using pEDA and HOMA descriptors. Excellent correlation $\left(R^{2}=0.988\right)$ between pEDA and aromaticity index HOMA was found. Depending on the electron donating/accepting power of substituents, the range of HOMA values was very large, between $\sim-0.5$ and $\sim 0.7$.

An application of natural bond orbital (NBO) [115] approach for SE transmission through fulvene and benzene ring systems [135] allows to look inside the transmission properties of these systems, undoubtedly related to changes in $\pi$ electron delocalization. When pEDA values of fulvene are plotted against the data for benzene, then regression has the slope equal to 1.44 with $c c=0.949$, indicating a strong $\pi$ electron accepting characteristic of fulvene ring, which contains $5 \pi$-electrons and tends to follow the Hückel rule; whereas in the case of benzene containing six electrons, no such effect takes place. Therefore, from the point of view of $\pi$ electron structure, fulvene is significantly more sensitive to SE than benzene. In the case of exocyclically substituted fulvene systems, for electron donating substituents, a good linear regression between HOMA and exocyclic $\mathrm{CC}$ bond

a)

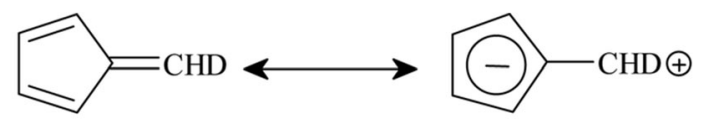

b)

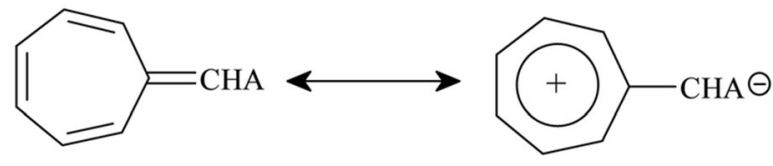

Scheme 4 Pentafulvene (a) and heptafulvene (b) 


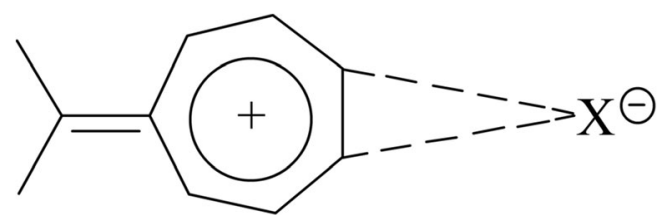

Scheme 5 Structure of heptafulvene-halogen atom complex $(\mathrm{X}=\mathrm{F}, \mathrm{Cl}$, $\mathrm{Br}, \mathrm{I}, \mathrm{At})$.

length (with the slope $=10.4$ and $c c=0.970$ ) is observed, whereas no correlation is found for other substituents. This is due to the strong electron attraction of a five-member ring, with a tendency to have six $\pi$-electrons.

Another weak or non-aromatic non-alternant $\pi$-electron system is heptafulvene (Scheme $4 b$ ). The aromaticity of its complexes with halogen atoms has been studied using HOMA, pEDA, and NICS indicators [136]. There are $7 \pi$ electrons in the heptafulvene ring, and thus its interaction with the halogen atoms (Scheme 5) leads to a charge transfer to the halogen and, as consequence, halogen anions are formed. This process results in a change of HOMA from 0.165 for the free molecule up to 0.640 for the fluorine salt. The smaller halogen atom, i.e., the more electronegative, the greater change is observed. The dependence of HOMA on the charge at halogen atoms has a correlation coefficient as high as $c c=-0.999$ ! The correlations between HOMA and pEDA is also excellent with $c c=-0.999$, as well as between binding energy and NICS $(c c=-0.995)$.

A wide overview of factors affecting aromaticity of monosubstituted derivatives of pentafulvene, benzene, and heptafulvene can be found [137].

An important group of aromatic systems is azoles, fivemembered heterocyclic compounds containing at least one nitrogen atom as part of the ring. The simplest, pyrrole, despite of its five-membered ring, is to some extent an analog to benzene because it contains six $\pi$-electrons. This is achieved due to the presence of $2 \mathrm{pz}$ electron pair at $\mathrm{NH}$ group in the ring, which in consequence leads to a dramatic change in the SE on aromaticity of the ring, as shown in Table 2 (data taken from Ref. [138]) In the case of benzene derivatives, the substituent significantly less affects the aromaticity of the ring.
Azoles containing various numbers of nitrogen atoms are further analogs of $6 \pi$-electron rings that have some aromatic properties. Difference between SE in benzene and pyrazole and imidazole, all of them containing six $\pi$-electrons, is excellently shown in Fig. 7 [139]. For electron-donating substituents $(\sigma<0)$ HOMA values are over 0.8 , whereas for electron withdrawing ones, HOMA are less than 0.8. In the latter case, substituents attract $\pi$-electrons from the ring, leading to a formation of systems not fulfilling $4 \mathrm{~N}+2$ rule.

Five-membered tetrazole contains four nitrogen atoms and similarly as benzene six $\pi$-electrons. Tetrazole exists in two tautomeric forms, notified as $1 H$ and $2 H$, as shown in Scheme 6. A comparison of the substituent effect in monosubstituted both tautomers of tetrazole and benzene derivatives on $\pi$-electron structure of these systems leads to interesting but diversified results [140]. The $\pi$-electron structure of the ring has been characterized by the pEDA index; 16 substituents were considered, with different $\pi$ - and sigma-donor/acceptor properties. In all three cases the pEDA index, describing the $\pi$-electron transfer from the substituent to the ring or vice versa, is well correlated with ${\sigma_{\mathrm{p}}}^{+}$constants. The more detailed analysis revealed that the dependence of $2 \mathrm{pz}$ orbital occupancies at carbon atoms of benzene in ortho and para positions on $\mathrm{pEDA}$ follows a linear trend with $c c=0.971$ and 0.968 , respectively. However, the same correlation for the carbon atom in the meta- position is worse $(c c=-0.791)$ and with the small opposite slope. It is again confirmed that the meta position differs in its interaction with substituents, and hence Hammett substituent constants for the meta and para positions are different.

Similar correlations were found for both $1 \mathrm{H}$ - and $2 \mathrm{H}$ - tetrazole derivatives. Occupations at $2 \mathrm{p}_{z}$ orbitals of all nitrogen atoms, except $\mathrm{N} 3$, correlate nicely with pEDA values $(c c \geq$ 0.95 ). The lack of the correlation with the $2 \mathrm{p}_{z}$ occupation at the N3 atom may suggest that this position in $1 \mathrm{H}$ - and $2 \mathrm{H}$ tetrazoles resembles to some extent the meta- position in the benzene series.

A similar study comparing $\mathrm{SE}$ in the case of $\mathrm{C}$ - and $\mathrm{N}$ monosubstituted pyrrole revealed that dependence of cSAR(NX) on cSAR(C3X) has the slope equal to 0.88 $\left(R^{2}=0.90\right)$, indicating the position C3 more sensitive to SE
Table 2 The lowest and the highest aromaticity indices (substituents are in parentheses) for monosubstituted benzenes and pyrroles (from ref. [138])

\begin{tabular}{|c|c|c|c|c|c|c|}
\hline \multirow{2}{*}{$\begin{array}{l}\text { Aromaticity } \\
\text { Indices }\end{array}$} & \multicolumn{3}{|l|}{$\mathrm{Ph}-\mathrm{X}$} & \multicolumn{3}{|l|}{ Pyr-X } \\
\hline & Lowest & Highest & $\Delta^{\mathrm{a}}$ & Lowest & Highest & $\Delta^{\mathrm{a}}$ \\
\hline HOMA & $0.90(\mathrm{Li})$ & $0.98(\mathrm{~F})$ & 0.08 & $0.61\left(\mathrm{BH}_{2}\right)$ & $0.90(\mathrm{~F})$ & 0.29 \\
\hline $\operatorname{NICS}(0)$ & $-6.72(\mathrm{Li})$ & $-9.99(\mathrm{~F})$ & -3.27 & $-9.22\left(\mathrm{BH}_{2}\right)$ & $-16.53(\mathrm{~F})$ & -7.31 \\
\hline NICS(1) & $-8.92\left(\mathrm{NH}_{2}\right)$ & $-10.37(\mathrm{Li})$ & -1.45 & $-8.21\left(\mathrm{BH}_{2}\right)$ & $-10.41(\mathrm{Li})$ & -2.20 \\
\hline NICS(1)zz & $-24.4\left(\mathrm{NH}_{2}\right)$ & $-28.83(\mathrm{H})$ & -4.43 & $-24.0\left(\mathrm{BH}_{2}\right)$ & $-32.86(\mathrm{Li})$ & -8.86 \\
\hline ASE & $126.24\left(\mathrm{BH}_{2}\right)$ & $139.31\left(\mathrm{BH}_{2}\right)$ & 13.07 & $35.32(\mathrm{~F})$ & $82.58(\mathrm{Li})$ & 47.25 \\
\hline
\end{tabular}

${ }^{\text {a }}$ Ranges of aromaticity index values between the most and the least aromatic molecules 


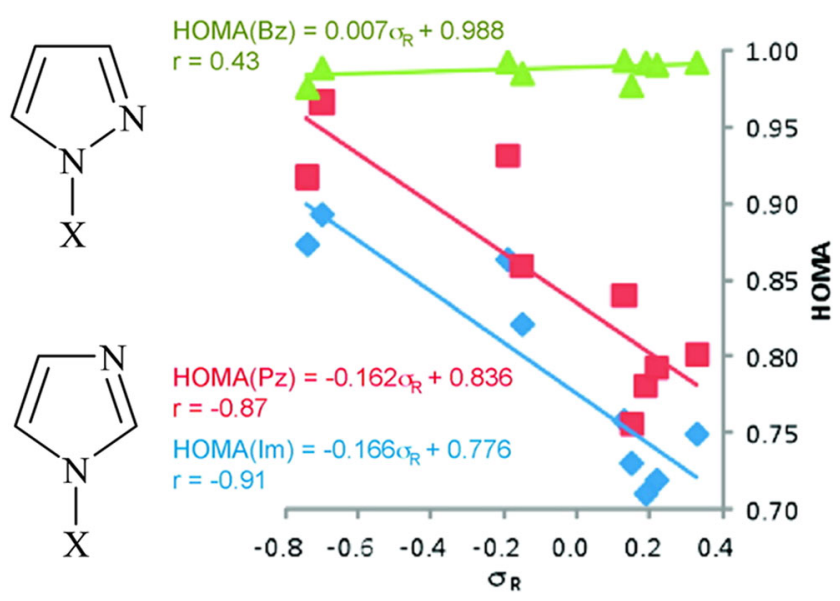

Fig. 7 Correlations between HOMA aromaticity index and resonance substituent constant $\left(\sigma_{\mathrm{R}}\right)$ for substituted benzene $(\mathrm{Bz})$, pyrazole $(\mathrm{Pz})$ and imidazole (Im) derivatives. Reprinted (adapted) from J Phys Chem A 115:8575 (2011) [139]. Copyright 2011 with permission from the American Chemical Society

[141]. It has also been shown that the electron-donating/electron-attracting properties of the substituents attached at $\mathrm{C} 3$ position are practically identical to those observed in the monosubstituted benzene derivatives.

Very interesting and not typical is a consideration of doubly bonded substituent to a five-membered ring [142], this is mono-double-bond substituted cyclopenta-1,3-dienes (cyclopenta-2,4-dienone analogs, CPDA). The resulting dependence of HOMA on NICS is non-linear, but it is undoubtedly acceptable, as shown in Fig. 8.

\section{Disubstituted $\pi$-electron systems}

Most of the typical applications of the Hammett rules apply to di-substituted $\pi$-electron systems of the X-R-Y type, where $\mathrm{Y}$ is a so-called "reaction site" or a fixed chemical group in the series, $\mathrm{X}$ is varying substituents, and $\mathrm{R}$ is a transmitter. The latter is the subject of our interest: how far $\mathrm{R}$ is affected by the substituent effect?

The first comprehensive analysis of the substituent effect on aromaticity in disubstituted benzene derivatives was presented by Cyranski and Krygowski [143, 144]. For this a)<smiles>[X]c1nnnn1[TlH]</smiles>

b)

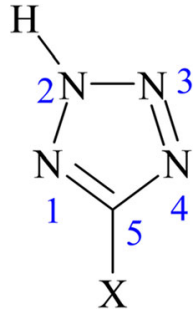

Scheme 6 C5-substituted $1 H$ - (a) and $2 H$ - tetrazoles (b). purpose, regression and factor analyses [145] of experimental molecular geometry [146, 147] of meta and para benzene derivatives (with $\mathrm{Y}=\mathrm{NO}_{2}, \mathrm{CN}, \mathrm{COOH}, \mathrm{Cl}, \mathrm{OH}$, and $\mathrm{NH}_{2}$ ) were performed. Then, the application of these methods to five geometry-based aromaticity indices (HOMA, BAC [63], $\mathrm{BE}$ [63], E(n) [63] and $\mathrm{I}_{6}$ [37]) for six reaction series of paradisubstituted X-Ph-Y revealed $[143,144]$ that: (i) geometric indices of aromaticity follow the Hammett rule with $\sigma_{\mathrm{p}}$, (ii) if $\mathrm{X}$ and $\mathrm{Y}$ with similar electron properties (both are either donating or withdrawing) are excluded, the observed correlation becomes much stronger, (iii) two orthogonal factors are sufficient to explain more than $95 \%$ of the total variance.

Systematic studies of the SE on $\pi$-electron delocalization estimated by HOMA and transmission properties of 3- and 4-disubstituted derivatives of benzene and cyclohexa-1,3-diene (CHD) were carried out using quantum chemistry-based descriptors: cSAR and SESE as well as traditional Hammett-like substituent constants. The results for the 4-substituted 1-nitro, and 1-hydroxy derivatives of CHD [122] are shown in Fig. 9. In both series, it was found that when electron properties of the substituents are opposite to those of the fixed group, the HOMA values correlate well with SESE, with a significant slope. This effect is not observed if $\mathrm{X}$ and $\mathrm{Y}$ have similar electron properties.

The transmission properties of the substituent from a given position to the reaction center can be described by the charge flow index (CFI) [122], defined as:

$\mathrm{CFI}=\operatorname{cSAR}(\mathrm{Y})-\mathrm{cSAR}(\mathrm{X})$

The comparison of the transmission of the substituent effect from positions 3- and 4- in the disubstituted CHD and

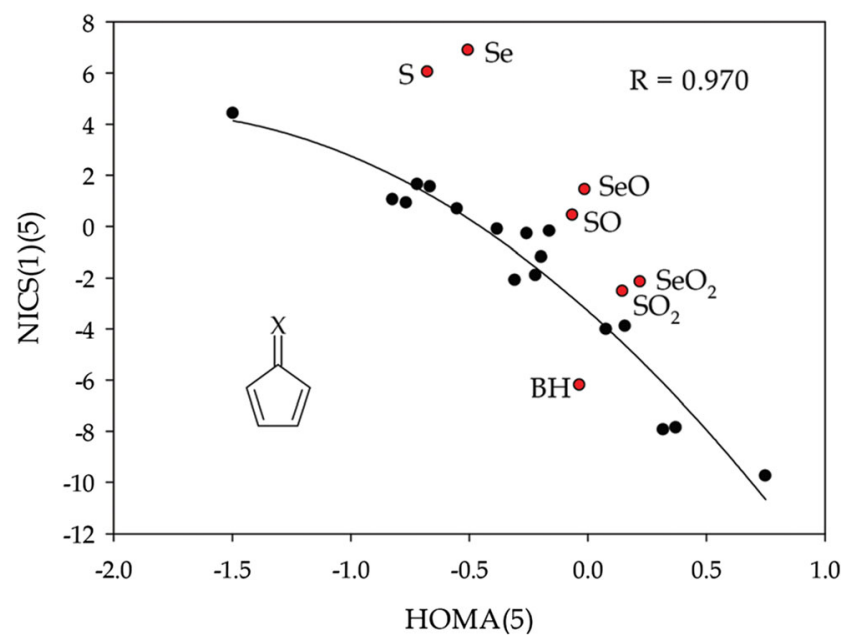

Fig. 8 Non-linear correlation between $\operatorname{HOMA}(5)$ and $\operatorname{NICS}(1)(5)$ indices for the CPDA systems. Reprinted from Org Biomol Chem 11:3008 (2013) [142]. Copyright 2013 with permission from The Royal Society of Chemistry 


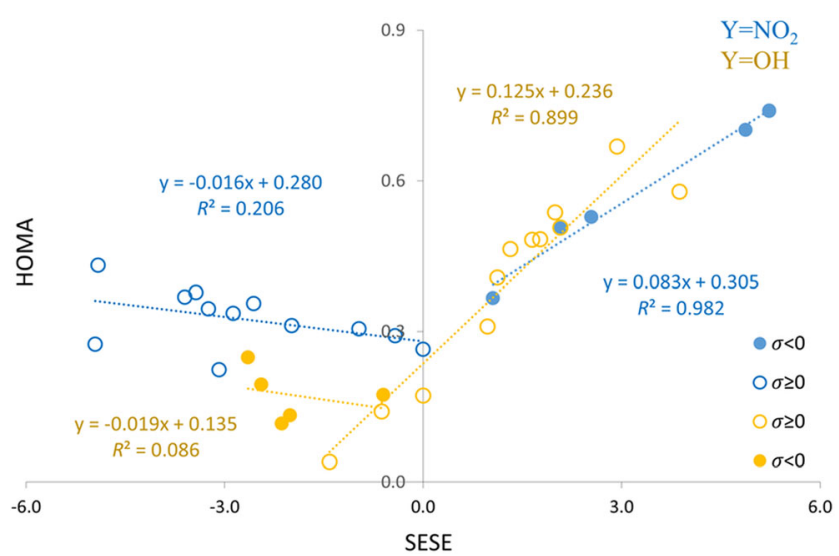

Fig. 9 Dependences of HOMA on SESE for 4-X-CHD-NO ${ }_{2}$ and 4-X$\mathrm{CHD}-\mathrm{OH}$ series. Reused from [122], this work is licensed under the Creative Commons Attribution 4.0 International License (http:// creativecommons.org/licenses/by/4.0/)

benzene series is shown in Table 3. Slope values of linear equations indicate weaker transmission from the meta (3-) position than from the para (4-) position, but in CHD much stronger this effect is observed than in benzene series. When HOMA values of the substituted nitrobenzene derivatives for the meta are plotted against the para positions [117], then the slope is 0.56 (with high $R^{2}=0.97$ ).

Some information regarding the discrepancy between the SE transmission in meta and para substituted derivatives can be drawn from the dependence of HOMA on $\operatorname{cSAR}(\mathrm{X})$ and SESE (as substituent effect descriptors), for substituted phenolates it is presented in Fig. 10 [118].

Again, as shown in these scatter plots, the energetic effect of SE is much smaller for meta-substituted species than for the para ones. The same is confirmed by changes in geometry (measured via HOMA) and $\operatorname{cSAR}(\mathrm{X})$ values.

Some light in the attempt to understand can come from the scatter plot of pEDA(Ring) vs sEDA(Ring) [117], presented in Fig. 11. As we can see, there is no general correlation between these two contributions to the description of the electronic structure of the transmitting ring.

The sEDA values depend on the $\pi$-electron properties of the substituent (compare sEDA of $\mathrm{NO}_{2}$ and $\mathrm{NH}_{2}$ groups), but another strong factor is electronegativity of the linking atom (nitrogen in both cases). Here, the Huheey concept of the group electronegativity may be to some extent helpful [92, 93].

How much the substituent can change the properties of the ring is shown in Fig. 12. The role of the intramolecular charge transfer is nicely documented when we look at the HOMA change due to the rotation of the nitro group in para-nitroanilines [148].

A specific interaction is observed in doubly bonded 1,4disubstituted benzene derivatives [142]. As in the case of systems with a double bonded substituent attached to a fivemembered ring (see above), the dependence of NICS on HOMA is non-linear, but excluding a few cases, well acceptable (see Fig. 13). Interestingly, the AIM parameters at ring critical points, such as electron density or Laplacian, correlate excellently with HOMA ( $c c=0.985$ and 0.988 , respectively). The same applies to a series of five-membered rings.

\section{Polysubstituted $\pi$-electron systems}

The polysubstituted $\pi$-electron systems, in addition to $\mathrm{Y}$ and $R$, contain several substituents $X_{1}, X_{2}, \ldots, X_{n}$ located at different $R$ positions.

It is well-known that substituted phenol derivative exhibit substantial changes in their acidity [149]. It is interesting, therefore, how changes in $\mathrm{OH}$ properties due to the influence of substituents affect aromaticity of the ring. The answer is given by the relationship between HOMA values and the $\mathrm{CO}$ bond lengths for 664 complexes of variously poly-substituted phenols interacting with various bases in the crystalline state [150], all data retrieved from the CSD database [146]. The dependence of HOMA on $d_{\mathrm{CO}}$ is shown in Fig. 14.

It is obvious that the stronger is the interaction of $\mathrm{OH}$ group with the base, the shorter becomes the $\mathrm{CO}$ bond and the more
Table 3 Values of the slope, $a$, and determination coefficient, $R^{2}$, for correlation between CFI for $1-$ 3 and 1-4 (meta and para) interactions in CHD and BEN derivatives (from ref. [122])

\begin{tabular}{|c|c|c|c|c|}
\hline \multirow[b]{2}{*}{$\mathrm{Y}$} & \multicolumn{2}{|c|}{$\mathrm{CFI}_{1-3}$ X-CHD-Y vs CFI $1-4$ X-CHD-Y } & \multicolumn{2}{|c|}{$\mathrm{CFI}_{1-3} \mathrm{X}-\mathrm{BEN-Y}$ vs CFI $\mathrm{Cl}_{1-4} \mathrm{X}-\mathrm{BEN}-\mathrm{Y}$} \\
\hline & $R^{2}$ & $a$ & $R^{2}$ & $a$ \\
\hline $\mathrm{NO}_{2}$ & 0.936 & 0.534 & 0.983 & 0.749 \\
\hline $\mathrm{COOH}$ & 0.942 & 0.560 & 0.984 & 0.779 \\
\hline $\mathrm{COO}^{-}$ & 0.925 & 0.529 & 0.983 & 0.783 \\
\hline $\mathrm{OH}$ & 0.952 & 0.597 & 0.988 & 0.842 \\
\hline $\mathrm{O}^{-}$ & 0.918 & 0.458 & 0.925 & 0.546 \\
\hline $\mathrm{NH}_{2}$ & 0.921 & 0.512 & 0.961 & 0.713 \\
\hline
\end{tabular}




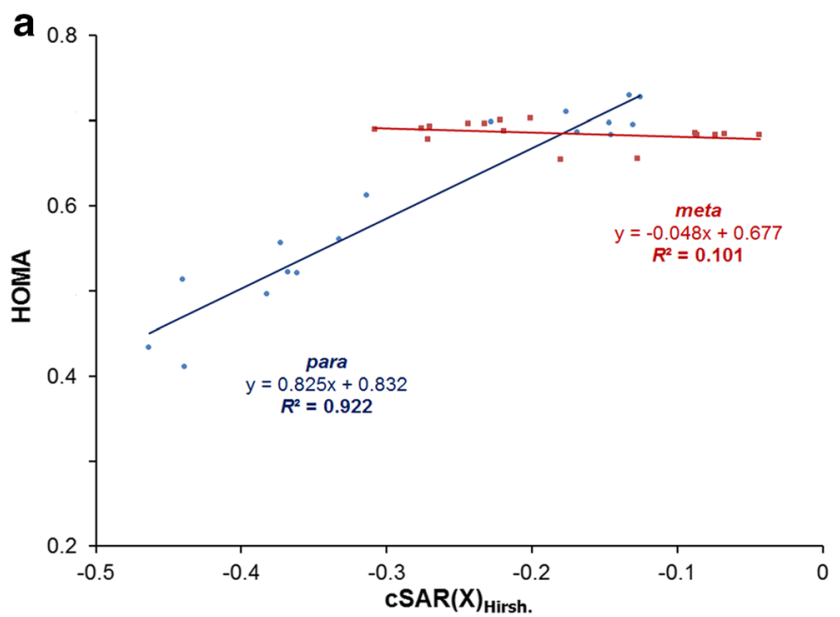

b

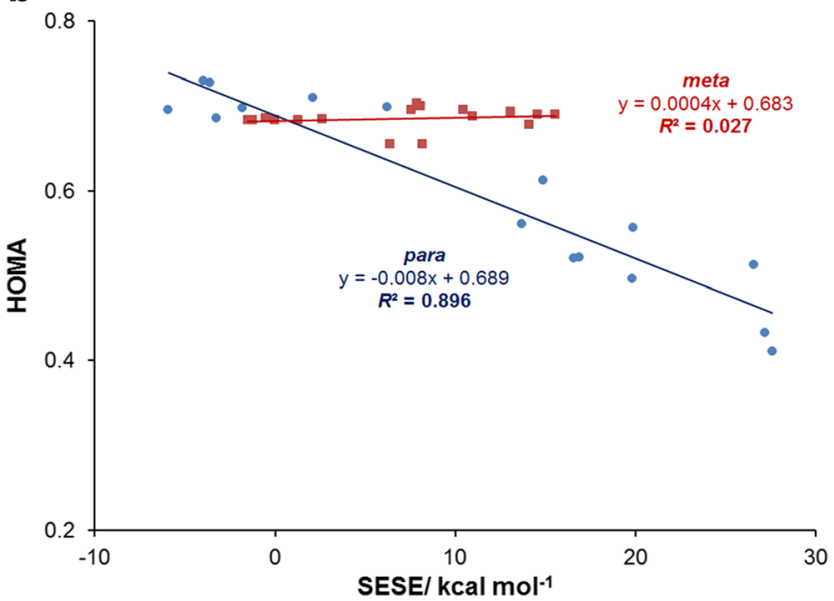

Fig. 10 Dependences of HOMA on a cSAR $(X)$ and $\mathbf{b}$ SESE in meta- and para-substituted phenolates. Reused from [118], this work is licensed under the Creative Commons Attribution 4.0 International License (http://creativecommons.org/licenses/by/4.0/)

localized $\pi$-electron structure of the ring and, in consequence, its less aromatic character. Simulation of this kind of interactions by quantum chemistry calculation, using a simple model for phenol and para-X-nitrophenols interacting with fluoride anion in a variable distance from the hydrogen atom of the hydroxyl group, leads to similar conclusions [151]. The HOMA and NICS values plotted against $d_{\mathrm{CO}}$ distance presented a similar picture: the higher the $d_{\mathrm{CO}}$ value, the more aromatic the ring is. The same was observed for substituent effect on proton transfer in para-substituted phenol complexes with fluoride anions [152].

Studies on exocyclically substituted derivatives of benzylic cations exhibit significant changes in aromaticity of the ring, which depend clearly on the varying charge at the exo-carbon atom [153]. The use of HOMA index and its values plotted against the exo-CC bond length and the charge of the exocarbon atom leads to acceptable correlations $(c c=0.845$ and $c c=0.88$, respectively). An application of the HOSE model

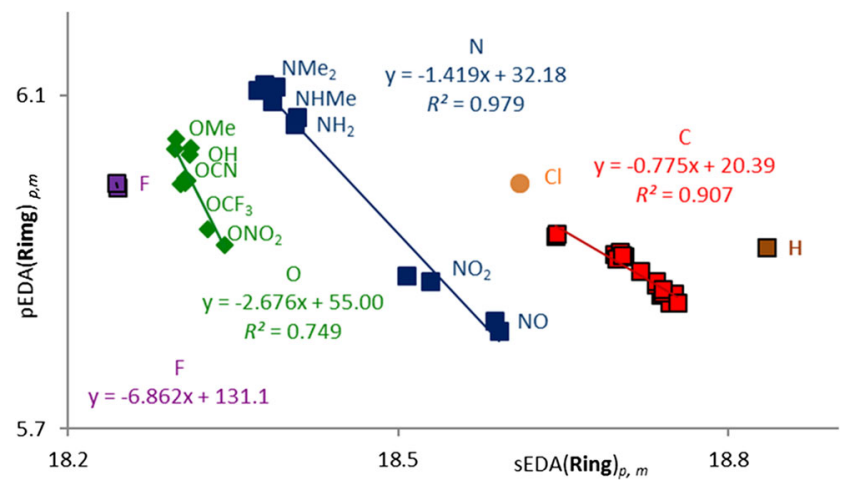

Fig. 11 Dependence of pEDA(Ring) on sEDA(Ring) for meta- and parasubstituted nitrobenzene derivatives. For red points the sequence is $\mathrm{Me}$, $\mathrm{CN}, \mathrm{CF}_{3}, \mathrm{CONH}_{2}, \mathrm{COOH}, \mathrm{COMe}, \mathrm{COCl}, \mathrm{CHO}$. Reprinted with permission from J Phys Chem A 121:5196 (2017) [117]. Copyright 2017 American Chemical Society

$[40,41]$ allowed to show that the contribution of resonance structures is also correlated with charge on the exo-carbon atom. When the problem is considered in relation to polycyclic benzenoid systems [154] an important conclusion has appeared: "If a single substituent able to form double bond is attached to the benzoid hydrocarbon in a position which permits the formation of the quinoidal structure along a larger part of the $\pi$-electron moiety, then it acts as dearomatizing factor for this fragment and in consequence for the whole system. Moreover, this effect is associated with a long-range intramolecular charge transfer from $\mathrm{CH}_{2}^{+}$group to the position(s) being the terminal (s) of the quinoidal structure in the molecule." It was also shown that the charge at $\mathrm{CH}_{2}{ }^{+}$group as well as aromaticity correlate well with the HammettStreitwieser position constants $[155,156]$.

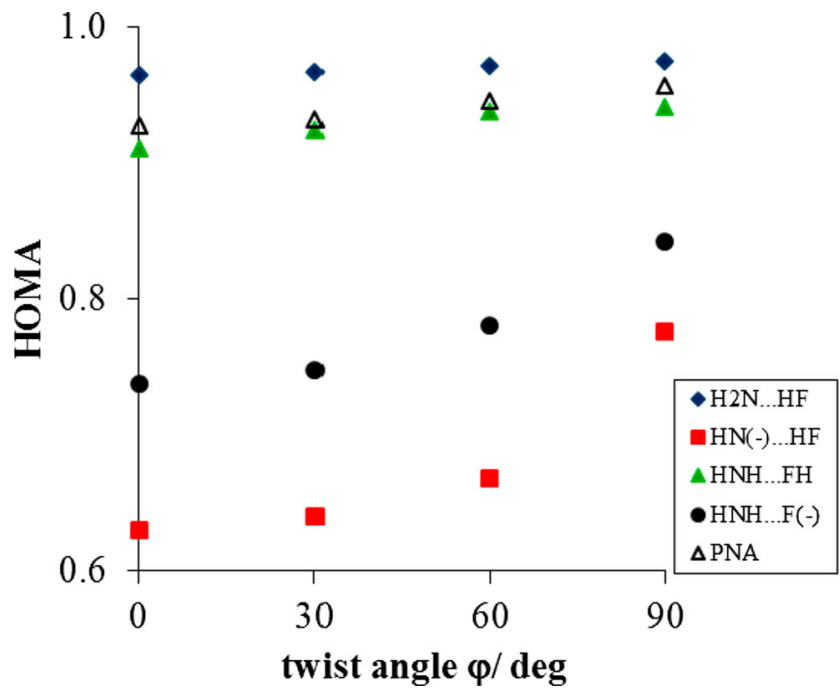

Fig. 12 Dependences of HOMA values on rotation angle $\varphi$ of $\mathrm{NO}_{2}$ group in para-nitroaniline complexes (for equilibrium structures, except for $\mathrm{HNH} \cdots \mathrm{F}^{-}$interactions). Reused from Crystals 6:29 (2016) [148], this work is licensed under the Creative Commons Attribution 4.0 International License (http://creativecommons.org/licenses/by/4.0/) 


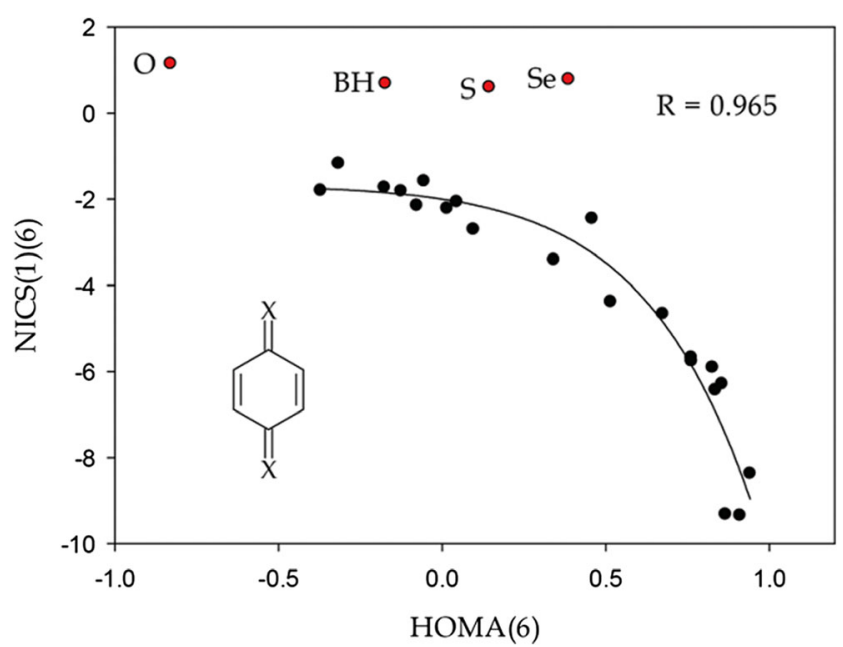

Fig. 13 Non-linear correlations between $\operatorname{NICS}(1)(6)$ and $\operatorname{HOMA}(6)$ indices for the BQA systems for di-double-bond substituted cyclohexa1,4-dienes ([1,4]benzoquinone analogs, BQA). Reprinted with permission from Org Biomol Chem 11:3006 (2013) [142]. Copyright 2013 with permission from The Royal Society of Chemistry

Among substituted derivatives of benzenoid hydrocarbons, the most localized $\pi$-electron systems are encountered in quinones. Hence, the study of the aromaticity and routes of $\pi$ electron delocalization in 4-substituted-1,2-benzoquinones (Scheme 7) is very interesting. The use of HOMA, MCI, DI, and FLU aromaticity indices and 11 substituents in position 4 (Scheme 7) gave insight into the nature of SE in these systems [157]. All the above-mentioned measures of $\pi$-electron delocalization revealed a very important feature of the studied systems. The substituents in the position 4 affect about nine times stronger the $\mathrm{C} 2 \mathrm{O}$ bond length than the $\mathrm{C} 1 \mathrm{O}$ one, as described by the slopes of the regression lines $\left(d_{\mathrm{CO}}\right.$ vs $\left.\sigma\right)-$ 0.0046 and -0.0005 .

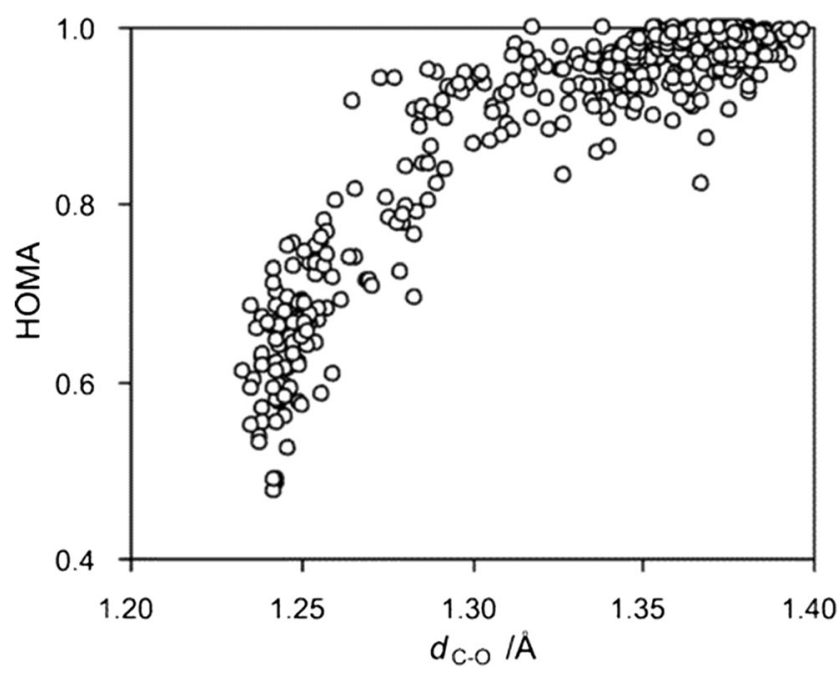

Fig. 14 Relationship of HOMA on $\mathrm{C}-\mathrm{O}$ bond length, $d_{\mathrm{C}-\mathrm{O}}$, for variously substituted phenols interacting with bases. Reprinted from J Chem Inf Comput Sci 44:2077 (2004) [150]. Copyright (2004) with permission from American Chemical Society

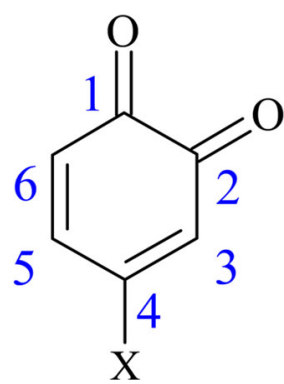

Scheme 7 4-substituted-1,2-benzoquinones, $\mathrm{X}=\mathrm{NO}, \mathrm{NO}_{2}, \mathrm{CN}, \mathrm{CHO}$, $\mathrm{H}, \mathrm{Me}, \mathrm{OMe}, \mathrm{OH}, \mathrm{NH}_{2}, \mathrm{NHMe}$, and $\mathrm{NMe}_{2}$

This picture is in line with much larger changes of HOMA and MCI descriptors of $\pi$-electron delocalization via $\mathrm{OC} 2 \mathrm{C} 3 \mathrm{C} 4$ than through $\mathrm{OC} 1 \mathrm{C} 6 \mathrm{C} 5 \mathrm{C} 4$. This observation was taken as a basis for a general statement that: "if the number of bonds between an electron accepting and electron donating atoms is even, then the intramolecular charge transfer is possible i.e. the resonance effect works" [157]. This is also in line with previous results, in which the traditional Hammett approach was used for meta- and para-substituted systems [82]. In addition to the important conclusions presented above, when the HOMA values of the ring of the studied systems are plotted against substituent constants, the linear regression has a good correlation $(c c=-0.930)$ : the stronger electron donating substituent, the higher value of HOMA.

onosubstituted 1,2- and 2,3-naphthoquinone derivatives have been the subject of studies on conjugated paths between $\mathrm{CO}$ groups and the substituents $\left(\mathrm{X}=\mathrm{NO}, \mathrm{NO}_{2}, \mathrm{CN}, \mathrm{CHO}, \mathrm{Me}\right.$, $\mathrm{OMe}, \mathrm{OH}, \mathrm{NH}_{2}, \mathrm{NHMe}$, and $\mathrm{NMe}_{2}$ ) [158]. The applications of the $\pi$-electron delocalization characteristics, such as FLU, DI, and HOMA, as well as changes in the CO bond lengths and SESE calculation, allowed for a better recognition of the problem. The results obtained revealed regression lines between these parameter values plotted against substituent constants, shown in Tables 4 and 5. In almost $50 \%$ of cases, correlation coefficients (in modulo) were better than 0.9. It should be noted, however, that conjugated path for the same substituent may be realized as illustrated in Fig. 15; to characterize each of them, the HOMA index was used.

It can be concluded that in both series of 1,2- and 2,3naphthoquinone derivatives, only one of the two carbonyl groups exhibits a better-defined substituent effect, characterized by both a higher correlation coefficient and more substantial values of slopes for $d_{\mathrm{C}=\mathrm{O}}$ vs $\sigma$ regressions (Tables 4 and 5). These are mostly cases where the number of bonds between donating atom of the substituent and oxygen atom of the carbonyl group is even. For odd numbers, no clear relations are observed.

Recent SE studies on aromaticity in variously substituted 1-, 2-, and 9-anthrols have revealed some interesting observations [159] $\left(\mathrm{X}=\mathrm{NO}_{2}, \mathrm{CN}, \mathrm{H}, \mathrm{OH}\right.$ or $\left.\mathrm{NH}_{2}\right)$. First, the variability of HOMA estimated for perimeter is very low, never greater than 0.023 , indicating a low sensitivity of aromaticity 
Table 4 Statistics of regression $(y=a \times \sigma+b)$ of bond lengths and DI values for both carbonyl groups, SESE, HOMA, and FLU values of the rings on substituent constants for 2,3-naphthoquinone derivatives, correlation coefficients (R) taken as modulo value (from ref. [158])

\begin{tabular}{|c|c|c|c|c|c|c|c|c|c|c|}
\hline \multirow[t]{6}{*}{ vs. $\sigma$} & \multicolumn{2}{|l|}{$\mathrm{CO}$} & \multicolumn{2}{|l|}{ DI } & \multicolumn{2}{|l|}{ HOMA } & \multicolumn{2}{|l|}{ FLU } & \multicolumn{2}{|l|}{ SESE } \\
\hline & $a$ & $b$ & $a$ & $b$ & $a$ & $b$ & $a$ & $b$ & $a$ & $b$ \\
\hline & $\begin{array}{l}\mathrm{CO}(2): R \\
-0.0015\end{array}$ & $\begin{array}{l}.99 \\
1.215\end{array}$ & $\begin{array}{l}\text { DI (2): } \\
0.0081\end{array}$ & $\begin{array}{l}.97 \\
1.435\end{array}$ & $\begin{array}{l}\text { Ring (A) } \\
-0.0206\end{array}$ & $\begin{aligned}= & 0.86 \\
& -1.262\end{aligned}$ & \multicolumn{2}{|c|}{ Ring (A): $R=0.44$} & \multicolumn{2}{|l|}{$R=0.93$} \\
\hline & \multicolumn{2}{|c|}{$\mathrm{CO}(3): R=0.59$} & \multicolumn{2}{|c|}{ DI (3): $R=0.70$} & \multicolumn{2}{|c|}{ Ring (B): $R=0.30$} & \multicolumn{2}{|c|}{$\operatorname{Ring}(\mathrm{B}): R=0.21$} & -2.1843 & \multirow[t]{2}{*}{-1.168} \\
\hline & $\begin{array}{l}\mathrm{CO}(2): K \\
-0.0002\end{array}$ & $\begin{array}{l}0.42 \\
1.214\end{array}$ & \multicolumn{2}{|c|}{$\mathrm{DI}(2): R=0.032$} & $\operatorname{Ring}(\mathrm{A}): R=0.97$ & $\begin{aligned}= & 0.97 \\
& -1.270\end{aligned}$ & $\begin{array}{l}\text { Ring (A) } \\
0.0017\end{array}$ & $\operatorname{Ring}(\mathrm{A}): R=0.90$ & $R=0.98$ & \\
\hline & \multicolumn{2}{|c|}{$\mathrm{CO}(3): R=0.99$} & $\begin{array}{l}\text { DI (3): } \\
0.0204\end{array}$ & $\begin{array}{l}.99 \\
1.432\end{array}$ & $\begin{array}{l}\text { Ring (B) } \\
-0.0099\end{array}$ & $\begin{aligned}= & 0.30 \\
& -0.022\end{aligned}$ & $\begin{array}{l}\text { Ring (B) } \\
-0.0001\end{array}$ & $\begin{array}{l}0.16 \\
0.037\end{array}$ & -3.5296 & -0.058 \\
\hline
\end{tabular}

(estimated in this way) on the SE. This is in line with an earlier finding that the perimeter bond lengths are little sensitive to any internal perturbations; moreover, the HOMA index estimated for perimeter leads to higher values than in cases when all bonds, i.e., perimeter and internal ones, are taken into account [160]. Second, HOMA values for individual rings are always lower than those for perimeter and usually the rings with the substituent present show a reduced HOMA value. Third, HOMA values for perimeter and individual rings in monosubstituted anthracene resemble those observed in analogously substituted anthrols. In addition, for the substituted 2-anthrol series, a long-distance substituent effect has been documented: the $\mathrm{OH}$ group is in the first ring, the substituent is attached to the middle ring, and the most sensitive to $\pi$-electron delocalization is the last ring.

Hydrogen-bonded complexes of exocyclic substituted derivatives of 2-methylene-2H-indene, shown in Fig. 16, can also be regarded as polysubstituted $\pi$-electron systems. A systematic study of the relationship between substituent effects and the aromaticity of a six-membered ring has recently been published [161]. To characterize $\pi$-electron delocalization HOMA, FLU, SA (Shannon aromaticity) [162] and

Table 5 Statistics of regression $(y=a \times \sigma+b)$ of bond lengths and DI values for both carbonyl groups, SESE, HOMA, and FLU values of the rings on substituent constants for 1,2-naphthoquinone derivatives, correlation coefficients (R) taken as modulo values (from ref. [158])

\begin{tabular}{|c|c|c|c|c|c|c|c|c|}
\hline vs. $\sigma$ & $\mathrm{CO}$ & DI & \multicolumn{2}{|c|}{ HOMA } & \multicolumn{2}{|c|}{$\overline{F L U}$} & \multicolumn{2}{|c|}{ SESE } \\
\hline str & $b$ & $b$ & $a$ & $b$ & $a$ & $b$ & $a$ & $b$ \\
\hline & $\mathrm{CO}(1): \mathrm{R}=0.63$ & $\mathrm{DI}(1): \mathrm{R}=0.47$ & \multicolumn{2}{|c|}{$\operatorname{Ring}(A): R=0.91$} & \multicolumn{2}{|c|}{$\operatorname{Ring}(\mathrm{A}): \mathrm{R}=0.82$} & \multirow{2}{*}{\multicolumn{2}{|c|}{$\mathrm{R}=0.97$}} \\
\hline & $-0.0004 \quad 1.209$ & $0.0013 \quad 1.451$ & -0.0510 & -1.300 & 0.0016 & 0.074 & & \\
\hline & $\mathrm{CO}(2): \mathrm{R}=0.97$ & $\mathrm{DI}(2): \mathrm{R}=0.97$ & \multicolumn{2}{|c|}{$\operatorname{Ring}(B): R=0.58$} & \multicolumn{2}{|c|}{$\operatorname{Ring}(B): R=0.52$} & \multirow{2}{*}{-4.8483} & \multirow{2}{*}{-1.082} \\
\hline & $-0.0037 \quad 1.213$ & $0.0234 \quad 1.436$ & -0.0037 & 0.962 & 0.0003 & 0.003 & & \\
\hline & $\mathrm{CO}(1): \mathrm{R}=0.85$ & $\mathrm{DI}(1): \mathrm{R}=0.79$ & \multicolumn{2}{|c|}{$\operatorname{Ring}(A): R=0.92$} & \multicolumn{2}{|c|}{$\operatorname{Ring}(\mathrm{A}): \mathrm{R}=0.81$} & \multirow{2}{*}{\multicolumn{2}{|c|}{$\mathrm{R}=0.99$}} \\
\hline & $\begin{array}{ll}-0.0009 & 1.209\end{array}$ & $0.0040 \quad 1.455$ & -0.0216 & -1.360 & 0.0020 & 0.076 & & \\
\hline & $\mathrm{CO}(2): \mathrm{R}=0.99$ & $\mathrm{DI}(2): \mathrm{R}=0.97$ & \multicolumn{2}{|c|}{$\operatorname{Ring}(B): R=0.67$} & \multicolumn{2}{|c|}{$\operatorname{Ring}(B): R=0.57$} & \multirow{2}{*}{-2.5707} & \multirow{2}{*}{-1.292} \\
\hline & $-0.0016 \quad 1.219$ & $0.0087 \quad 1.443$ & 0.0128 & 0.953 & -0.0009 & 0.005 & & \\
\hline & $\mathrm{CO}(1): \mathrm{R}=0.99$ & $\mathrm{DI}(1): \mathrm{R}=0.99$ & \multicolumn{2}{|c|}{$\operatorname{Ring}(A): R=0.99$} & \multicolumn{2}{|c|}{$\operatorname{Ring}(A): R=0.79$} & \multirow{2}{*}{\multicolumn{2}{|c|}{$\mathrm{R}=0.99$}} \\
\hline & $-0.0027 \quad 1.210$ & $0.0156 \quad 1.449$ & -0.0593 & -1.355 & 0.0021 & 0.076 & & \\
\hline & $\mathrm{CO}(2): \mathrm{R}=0.90$ & $\mathrm{DI}(2): \mathrm{R}=0.80$ & \multicolumn{2}{|c|}{$\operatorname{Ring}(B): R=0.81$} & \multicolumn{2}{|c|}{$\operatorname{Ring}(B): R=0.73$} & -3.1345 & -1.334 \\
\hline & $-0.0007 \quad 1.212$ & $0.0022 \quad 1.445$ & 0.0194 & 0.954 & -0.0014 & 0.005 & & \\
\hline & $\mathrm{CO}(1): \mathrm{R}=0.91$ & $\mathrm{DI}(1): \mathrm{R}=0.76$ & Ring(A): & $\mathrm{R}=0.82$ & Ring(A): & $=0.69$ & & \\
\hline & $\begin{array}{ll}-0.0007 & 1.209\end{array}$ & $0.0020 \quad 1.453$ & -0.0276 & -1.330 & 0.0013 & 0.075 & & \\
\hline & $\mathrm{CO}(2): \mathrm{R}=0.97$ & $\mathrm{DI}(2): \mathrm{R}=0.91$ & Ring(B): & $\mathrm{R}=0.57$ & Ring(B): & $=0.46$ & 12406 & 1655 \\
\hline & $-0.0012 \quad 1.212$ & $0.0051 \quad 1.442$ & 0.0121 & 0.940 & -0.0006 & 0.005 & -1.2490 & $-1.03 \mathrm{~J}$ \\
\hline
\end{tabular}


<smiles>[X]c1ccc2c(c1)=CC(=O)C(=O)C=2</smiles>

$y=-0.0227 x+0.0559$<smiles>[X]C1=CC2=CC(=O)C(=O)CC2C=C1</smiles>

$$
\begin{gathered}
\mathbf{R}=\mathbf{0 . 8 8} \\
\mathrm{y}=0.0467 \mathrm{x}+0.2141
\end{gathered}
$$

Fig. 15 Dependences of HOMA for conjugation paths on substituent constants for 6-substituted 2,3-naphthoquinone derivatives (N: number of bonds between X and oxygen atoms). Reprinted from J Phys Chem A 115:12691 (2011) [158]. Copyright 2011 with permission from American Chemical Society

NICS(1)zz aromaticity indices were used. Both in the case of isolated monomers and $\mathrm{H}$-bonded complexes, excellent linear correlations $\left(R^{2} \geq 0.97\right)$ were found between aromaticity indices and the substituent constants. The aromaticity of the sixmembered rings increases with an increase in the electrondonating character of the $\mathrm{X}$ substituents. In addition, the strength of the resulting $\pi$-hydrogen bond (energy in the range of 4.0 to $7.0 \mathrm{kcal} / \mathrm{mol}$ ) depends on the aromaticity of the sixmembered ring and increases with increasing aromaticity. It can therefore be said that a long-distance substituent effect also works in this case.

\section{Substituent effects in quasi-aromatic systems}

The term quasi-aromatic compounds was introduced by Lloyd and Marshall [163] and then supported by studies of metal complexes of acetyloacetone, which are characterized by the ease with which they undergo electrophilic substitution at the $\beta$ carbon $[164,165]$. Quasi-aromatic

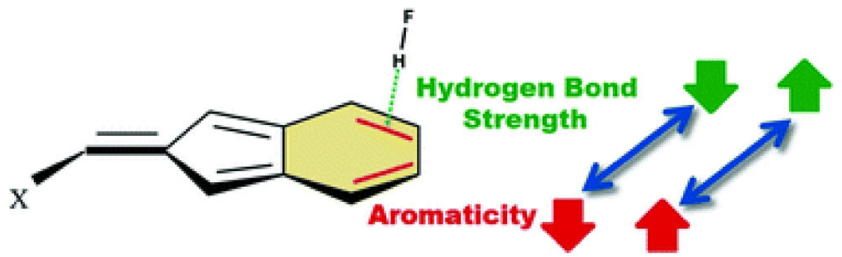

$\mathrm{X}: \mathrm{NO}_{2}, \mathrm{CN}_{2} \mathrm{CF}_{3}, \mathrm{CCH}, \mathrm{H}, \mathrm{CHCH}_{2}, \mathrm{t}=\mathrm{Bu}, \mathrm{Me}$, $\left.\mathrm{SMc}, \mathrm{OMc}, \mathrm{OH}, \mathrm{NH}_{2}, \mathrm{~N}_{(\mathrm{Mc}}\right)_{2}, \mathrm{NHMc}$

Fig. 16 Mutual effects of substituents and H-bonding strength on aromaticity of a six-membered ring for exocyclic substituted derivatives of 2methylene-2H-indene; graphical abstract reprinted from Phys Chem Chem Phys 21:623-630 [161] with permission from the PCCP Owner Societies

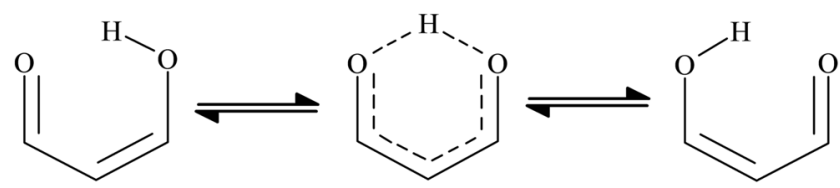

Scheme 8 Structures of enol form of malonaldehyde.<smiles>[X]C(=O)C([X])=C([X])OO</smiles>

(a)<smiles>[X]C(=O)C([Y4])=C([Y])O</smiles>

(b)
Scheme 9 Structural scheme of studied malonaldehyde derivatives for two conformations: a bridged, $\mathbf{b}$ open; $\mathrm{X} 1, \mathrm{X} 2$, and $\mathrm{X} 3$ denote $\mathrm{H}$ or $\mathrm{F}$ or $\mathrm{Cl}$.

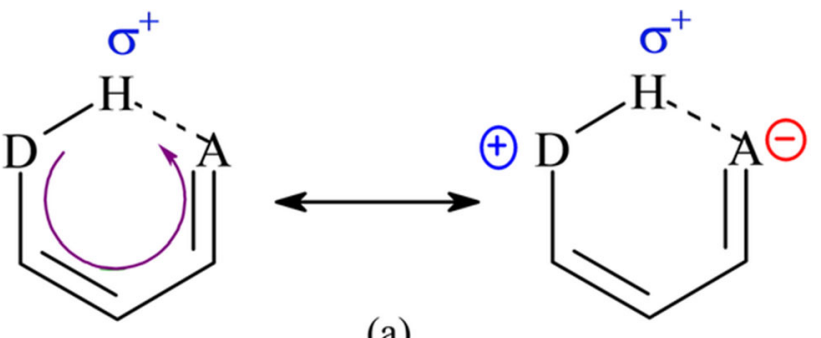

(a)
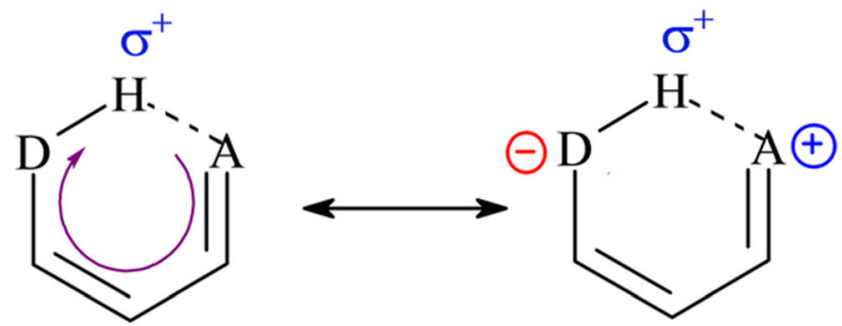

(b)

Fig. 17 The direction of resonance effect along the quasi-aromatic ring and its influence on H-bonding strength: the strengthening (a) and weakening (b) of the H-bond. Reprinted from Tetrahedron 71:4899 (2015) [171]. Copyright (2015), with permission from Elsevier 
Table 6 Relative energies (in $\mathrm{kcal} / \mathrm{mol}$ ) of several structures of different isomers of quasi-aromatic H-bonded rings (from ref. [172])

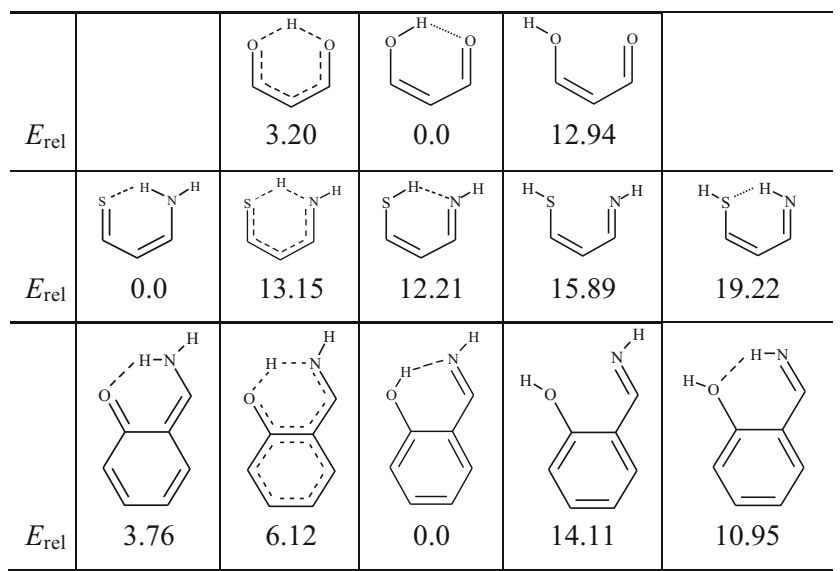

rings are best pictured by structures of enol forms of malonaldehyde, shown in Scheme 8. Their properties can be changed by substituents [166], Scheme 9 , or the hydrogen atom of the quasi-ring can be replaced by some metal atoms, e.g., $\mathrm{Li}$ or $\mathrm{BeH}[167]$.

An application of the HOMA approach to the covalent bonds of the quasi-aromatic rings and NICS to the center of the ring leads to the conclusion that NICS is insensitive to $\pi$-electron delocalization in the quasi-ring. In contrast, HOMA values for variously substituted malonaldehyde span the values between 0.472 and 0.870 [166]. However, if the hydrogen atom in the quasi-ring in malonaldehyde is replaced by $\mathrm{Li}$, then changes in delocalization in the spacer (OCCCO) are insignificant, the HOMA index is between 0.927 and 0971 [167]. Thus, in this case, the quasi-aromatic ring of malonaldehyde resembles the truly aromatic one, benzene, which is known to be weakly sensitive to the substituent effect [168]. The energy difference in bridged and open conformations is $12.96 \mathrm{kcal} / \mathrm{mol}$, while the differences in bond lengths for single $\mathrm{C}-\mathrm{O}$ and double bonds are $0.043 \AA$ and $0.119 \AA$, respectively [169]. A detailed discussion of resonance structures of 1(3)- and 2-X substituted malonaldehyde $\left(\mathrm{X}=\mathrm{NO}, \mathrm{NO}_{2}, \mathrm{CN}, \mathrm{CHO}, \mathrm{F}\right.$, $\mathrm{H}, \mathrm{CH}_{3}, \mathrm{OCH}_{3}, \mathrm{OH}$, and $\mathrm{NH}_{2}$.) was presented by Palusiak et al. [170]. The direction of the resonance effect along the quasi-aromatic ring and its influence on H-bonding strength is well illustrated by a scheme in Fig. 17 [171].

In a more quantitative, energetic way [172], this problem is presented in Table 6. Energy relations between various mesomeric structures of quasi-aromatic $\mathrm{H}$-bonded rings for malonaldehyde and alike analogs reveal dependence on structural feature of these systems.

The problem of a relation between $\pi$-electron delocalization in the quasi-ring and a strength of H-bonding, as well as Li-bonding, is clearly presented for salicylaldehyde, o-hydroxy Schiff base, o-nitrosophenol, and their lithium analogs [173]. In addition, detailed studies on the role of quasi-aromatic rings attached to benzenoid hydrocarbons reveal that they can also simulate real aromatic rings $[169,174]$. It is well known that the central ring of triphenylene is, in line with the Clar rules, "empty" from $\pi$-electrons or in other words is not aromatic, its HOMA value is 0.17 . When the triphenylene is simulated by its analog, where three benzene rings are replaced by three quasi-rings (see Fig. 18) and their hydrogen atoms are replaced by $\mathrm{Li}$, then we find that an increase in number of $\mathrm{Li}$ (replacing hydrogen) is associated with a dramatic decrease in central ring aromaticity. It is documented by both aromaticity indices, HOMA and NICS, as shown in Fig. 18. In other words, the more quasi-aromatic rings with lithium bonds attached to the benzene ring in the triphenylene analog, the lower aromaticity of the central benzene ring.

The extension of this approach into 33 phenolic rings and a set of 20 quasi-rings (formed by intramolecular hydrogen and lithium bonds) has revealed that charge and Laplacian, as well as energy and its components as kinetic and potential energies, estimated in ring critical points are well correlated with HOMA and NICS's
Fig. 18 Dependences of HOMA and NICS on the number of $\mathrm{Li}$ replacing $\mathrm{H}$ atoms in the quasiring. Reprinted from J Org Chem 116:7681 (2006) [174]. Copyright 2006 with permission from American Chemical Society
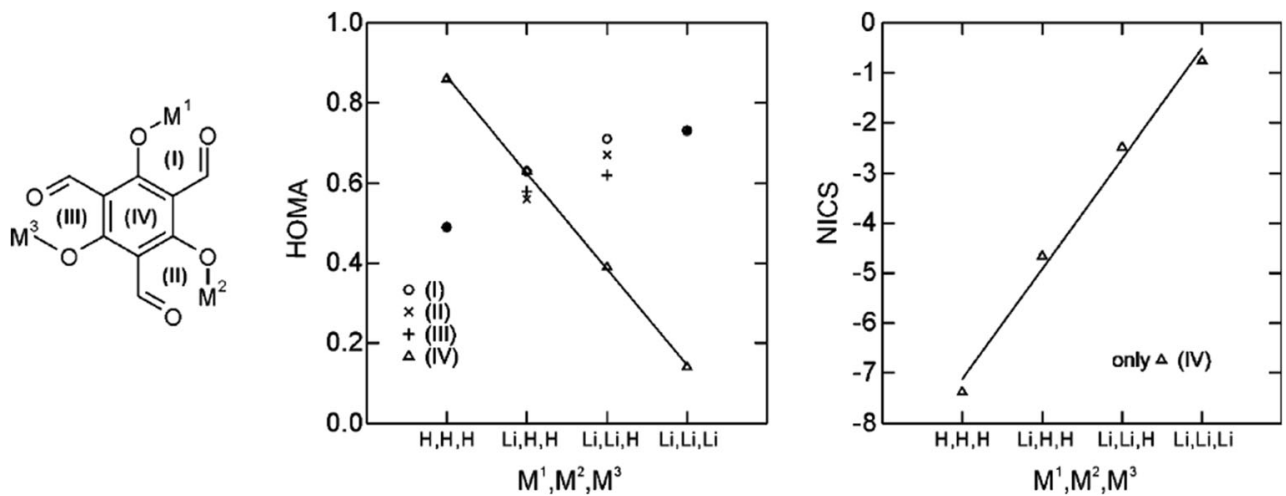
Scheme 10 Tautomeric and canonical forms of ortho-hydroxy Schiff base (a) and its studied derivatives (b).

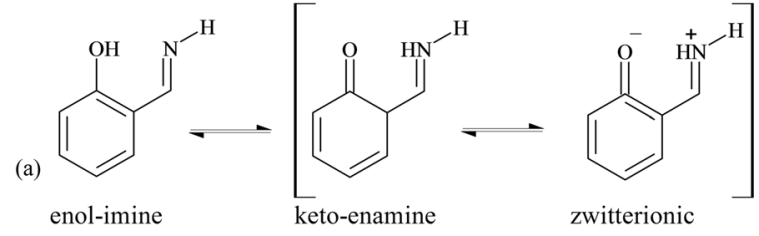

(b)

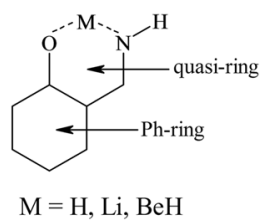

(NICS, NICS(1) and NICS(1) zz) values [56]. The study was carried out by comparing the above-mentioned aromaticity indices of benzene, naphthalene, anthracene, phenanthrene and triphenylene with their analogs in which one benzene ring was replaced with a quasiaromatic ring. The obtained results strongly confirmed the statement that the attached quasi-aromatic rings really simulate these aromatic ones. However, it should be noted again that, unlike HOMA, the NICS values do not describe electron delocalization in quasi- aromatic rings.

The problem of interrelations between $\pi$-electron delocalization in quasi-ring and benzene for ortho-hydroxy Schiff base and its derivatives, in which $\mathrm{H}$ atom of quasiaromatic ring is replaced by $\mathrm{Li}$ or $\mathrm{BeH}$ (Scheme 10) was also investigated [167]. For this purpose, calculations on two levels of theory (B3LYP/6-311+G** and MP2/aug-ccpVDZ) were used. Detailed information on the relation between quasi-ring in open and closed conformations and their influences on benzene ring [167] is gathered in Table 7.

The results obtained can be summarized as follows: (i) despite different calculation methods and level of applied quantum chemistry, the results are in a good qualitative agreement; (ii) $\pi$-electron delocalization of the benzene ring is weakly sensitive to the conformation of open or closed H-enol imine, but dramatically sensitive when H-keto-enamine is formed, (iii) $\pi$-electron delocalization in a closed quasi-ring increases in the sequence: $\mathrm{H}, \mathrm{Li}$ and $\mathrm{BeH}$, which is associated with

Table 7 Calculated HOMA and NICS $(1)_{z z}$ values, and delocalization energies $\left(E_{\mathrm{del}}\right.$, in $\left.\mathrm{kcal} \mathrm{mol}^{-1}\right)$ for ortho-hydroxy Schiff base and its derivatives (Scheme 10); B3LYP/6-311+G(d,p) results (from ref. [167])

\begin{tabular}{|c|c|c|c|c|}
\hline \multirow[t]{2}{*}{ System } & \multicolumn{2}{|l|}{ HOMA } & \multirow{2}{*}{$\begin{array}{l}\text { NICS }(1)_{z z} \\
\text { quasi-ring }\end{array}$} & \multirow[t]{2}{*}{$E_{\text {del }}$} \\
\hline & Ph-ring & quasi-ring & & \\
\hline H-enol-imine & 0.93 & 0.38 & -27.15 & 8.00 \\
\hline H-enol-imine (open) & 0.95 & 0.09 & -28.36 & -6.20 \\
\hline H-enol-enamine & 0.39 & 0.57 & -12.94 & \\
\hline Li-enol-imine derivative & 0.70 & 0.58 & -21.38 & 27.60 \\
\hline $\mathrm{BeH}$-enol-imine derivative & 0.82 & 0.70 & -24.07 & 32.30 \\
\hline Schiff anion & 0.42 & 0.25 & -17.02 & \\
\hline
\end{tabular}

irregular decrease of delocalization in benzene ring, estimated by HOMA and NICS.

A similar problem, for tautomeric interconversions (Scheme 11) and rotational isomerism in $o$-nitrosophenol [175], is illustrated in Fig. 19. Tautomeric forms of $o$ nitrosophenol differ dramatically in their $\pi$-electron delocalization. For the most stable isomers of the studied tautomers (shown in Scheme 11), low HOMA values characterize both benzene and quasi-rings in the ketoxime $(0.25$ and 0.40 , respectively), while for the nitrosole form they are 0.91 and 0.69 , respectively.

\section{Conclusions}

Phenomena known as aromaticity and the substituent effect are one of the most important issues in chemistry, biochemistry, and related fields. The indices based on energy, geometry (e.g., HOMA), magnetic (e.g., NICS), and electronic structure properties (e.g., FLU) are the most commonly used for the quantitative description of aromaticity. In the case of the substituent effect, it is most often characterized by substituent constants (e.g., Hammett substituent constants). However, the development of computational methods has led to the use of substituent effect descriptors based on quantum chemistry methods. For this purpose, the energies of properly designed homodesmotic reactions, electron density distribution, or electrostatic potential are used. However, in these cases, their use is verified by comparing the "new" descriptors with that obtained using the classical approach (i.e., Hammett-like constants). Among the new physicochemical concepts of the substituent effect the most promising is the cSAR approach, which allows to study both the classical and reverse substituent effect.

The mutual relations between aromaticity and the substituent effect can be summarized as follows:

(i) Strongly aromatic molecules are resistant to substituent effects. The less aromatic system, the more sensitive to SE.

(ii) Quasi-aromatic rings, when attached to a truly aromatic hydrocarbon, simulate well the "original" aromatic rings, alike benzene. 
<smiles></smiles>

(a)

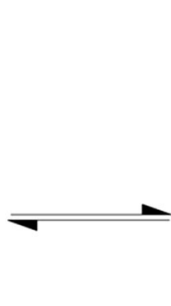<smiles></smiles>

(b)
Scheme 11 Tautomeric equilibria in $o$-nitrosophenol: a ketoxime and b nitrosoenol forms

(iii) NICS as an aromaticity descriptor does not work for the detection of $\pi$-electron delocalization in quasi-aromatic rings.

(iv) HOMA and FLU describe well $\pi$-electron delocalization in $\pi$-fragments of any $\pi$-electron systems.

(v) HOMA values estimated for perimeter bond lengths are very weakly sensitive to the substituent effect.

(vi) When the number of bonds between the electronattracting and electron-donating atoms of groups in the $\pi$-electron system is even, then the intramolecular charge transfer is much more effective than in any other cases.

(vii) Almost all SE descriptors indicate much smaller result of interactions in substituted systems for 1,3- positions (the meta like) than for 1,4- ones (the para like).

(viii) For larger systems a long-distance substituent effect has been found.

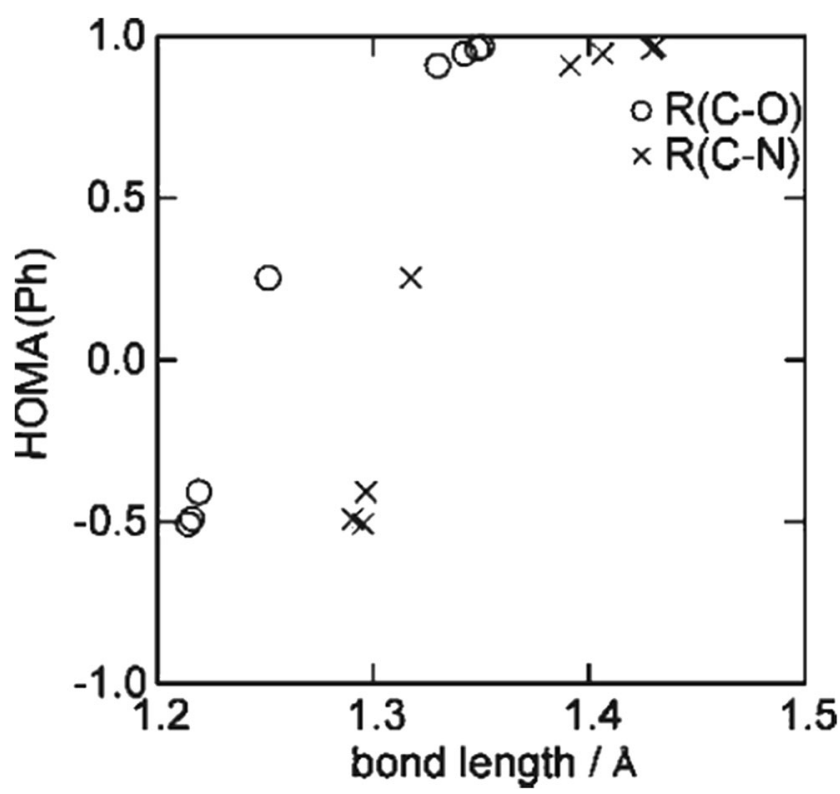

Fig. 19 Scatter plots of HOMA for phenyl ring vs. R(C-O) and $\mathrm{R}(\mathrm{C}-\mathrm{N})$ for various forms of $o$-nitrosophenol. Taken from J Phys Org Chem 18:892 (2005) [175]. Copyright (2005) Wiley-VCH Verlag GmbH \& Co. KGaA. Reproduced with permission
Acknowledgments HS thanks the Warsaw University of Technology for supporting this work.

Open Access This article is distributed under the terms of the Creative Commons Attribution 4.0 International License (http:// creativecommons.org/licenses/by/4.0/), which permits unrestricted use, distribution, and reproduction in any medium, provided you give appropriate credit to the original author(s) and the source, provide a link to the Creative Commons license, and indicate if changes were made.

\section{References}

1. ISI Web of science, retrieved in December 2018

2. Kekule' A (1865). Bull Soc Chim Fr 3:98-110

3. Erlenmayer E (1866) 137: 327-359

4. Chen Z, Wannere CS, Corminboeuf C, Puchta R, Schleyer PR (2005). Chem Rev 105:3842-3888

5. Robinson R (1958). Tetrahedron 3:323-324

6. Pauling L, Sherman J (1933). J Chem Phys 1:606-617

7. Pauling L (1960) The nature of the chemical bond. Cornell Univ Press, Ithaca, p 195

8. Streitwieser Jr A (1961) Molecular orbital theory for organic chemists. Wiley, New York, p 237ff

9. Cohen N, Benson SW (2001). Chem Rev 93:2419-2438

10. Slayden SW, Liebman JF (2001). Chem Rev 101:1541-1566

11. Dewar MJS, Gleicher GJ (1965). J Am Chem Soc 87:692-696

12. Dewar MJS, de Llano C (1969). J Am Chem Soc 91:789-795

13. Dewar MJS, Harget A, Trinajstić N (1969). J Am Chem Soc 91: 6321-6325

14. Cyrański MK (2005). Chem Rev 105:3773-3811

15. Hess Jr BA, Schaad LJ (1971). J Am Chem Soc 93:305-310

16. Hess Jr BA, Schaad LJ (1971). J Am Chem Soc 93:2413-2416

17. Hess Jr BA, Schaad LJ (1971). J Organomet Chem 36:3418-3423

18. Hess Jr BA, Schaad LJ (1973). J Am Chem Soc 95:3907-3912

19. Schaad LJ, Hess Jr BA (2001). Chem Rev 101:1465-1476

20. Kruszewski J, Krygowski TM (1970). Tetrahedron Lett 11:319 324

21. Smith MB, March J (2001) March's advanced organic chemistry5th edn. Wiley, New York, p 681

22. Krygowski TM (1970). Tetrahedron Lett 11:1311-1312

23. Dewar MJS, Gleicher GJ (1965). J Am Chem Soc 87:685-692

24. Figeys HP (1970). Tetrahedron 26:5225-5234

25. Krygowski TM, Kruszewski J (1972). Bull Acad Polon Sci Ser Sci Chim 20:993-1000

26. Julg A, Francoise P (1967). Theor Chim Acta 7:249-259

27. Kemula W, Krygowski TM (1968). Tetrahedron Lett 9:51355140

28. Kruszewski J, Krygowski TM (1972). Tetrahedron Lett 13:3839_ 3842

29. Krygowski TM (1993). J Inf Comput Sci 33:70-78

30. Madura ID, Krygowski TM, Cyrański MK (1998). Tetrahedron 54:14913-14,918

31. Zborowski KK, Proniewicz LM (2009). Pol J Chem 83:477-484

32. Zborowski KK, Alkorta I, Elguero J, Proniewicz LM (2012). Struct Chem 23:595-600

33. Zborowski KK, Alkorta I, Elguero J, Proniewicz LM (2013). Struct Chem 24:543-548

34. Andrzejak M, Kubisiak P, Zborowski KK (2013). Struct Chem 24 1171-1184

35. Raczyńska ED, Hallman M, Kolczyńska K, Stepniewski T (2010). Symmetry 2:1485-1509

36. Frizzo CP, Martins MAP (2012). Struct Chem 23:375-380

37. Bird CW (1985). Tetrahedron 41:1409-1414 
38. Bird CW (1992). Tetrahedron 48:335-340

39. Gordy W (1947). J Chem Phys 15:305-310

40. Wieckowski T, Krygowski TM (1981). Can J Chem 59:16221629

41. Krygowski TM, Anulewicz R, Kruszewski J (1983). Acta Cryst B39:732-739

42. Hendricson JB, Cram DJ, Hammond GS (1980) Organic chemistry4th edn. McGraw-Hill, New York, p 148

43. Randic M (1977). Tetrahedron 33:1905-1920

44. Ciesielski A, Krygowski TM, Cyranski MK, Balaban AT (2011). Phys Chem Chem Phys 13:3737-3747

45. Krygowski TM, Szatyłowicz H, Stasyuk OA, Dominikowska J, Palusiak M (2014). Chem Rev 114:6383-6422

46. Dauben HJ, Wilson JD, Laity JL (1968). J Am Chem Soc 90:811813

47. Benson RC, Flygare WH (1970). J Am Chem Soc 92:7523-7529

48. Flygare WH (1974). Chem Rev 74:653-687

49. Schleyer PR, Maerker C, Dransfeld A, Jiao H, van Eikema Hommes NJR (1996). J Am Chem Soc 118:6317-6318

50. Cyrański MK, Krygowski TM, Wisiorowski M, van Eikema Hommes NJR, Schleyer PR (1998). Angew Chem Int Ed 37: $177-180$

51. Corminboeuf C, Heine T, Seifert G, Schleyer PR, Weber J (2004). Phys Chem Chem Phys 6:273-276

52. Bader RFW (1992) Atom in molecules. A Quantum Theory. Oxford University Press, Oxford

53. Bader RFW (1991). Chem Rev 91:893-928

54. Popelier P (2000) Atoms in molecules, an introduction. Printice Hall

55. Howard ST, Krygowski TM (1997). Can J Chem 75:1174-1181

56. Palusiak M, Krygowski TM (2007). Chem Eur J 13:7996-8006

57. Poater J, Fradera M, Duran M, Sola M (2003). Chem Eur J 9:400 406

58. Bultinck P, Rafat M, Ponec R, Van Gheluwe B, Carbó-Dorca R, Popelier P (2006). J Phys Chem A 110:7642-7648

59. Matito E, Duran M, Sola M (2005). J Chem Phys 122:14109

60. Feixas F, Matito E, Poater J, Sola M (2015). Chem Soc Rev 44: 6434-6451

61. Katritzky AR, Barczyński P, Musumarra G, Pisano D, Szafran M (1989). J Am Chem Soc 111:7-15

62. Schleyer PR, Freeman PK, Jiao H, Goldfuss B (1995). Angew Chem Int Ed 34:337-340

63. Krygowski TM, Ciesielski A, Bird CW, Kotschy A (1995). J Chem Inf Comput Sci 35:203-210

64. Katritzky AR, Karelson M, Sild S, Krygowki TM, Jug K (1998). J Organomet Chem 63:5228-5231

65. Sadlej-Sosnowska N (2001). J Organomet Chem 66:8737-8743

66. Cyrański MK, Krygowski TM, Katritzky AR, Schleyer PR (2002). J Organomet Chem 67:1333-1338

67. Feixas F, Matito E, Poater J, Sola M (2008). J Comput Chem 29: $1543-1554$

68. Oziminski WP, Dobrowolski JCZ (2009). J Phys Org Chem 22: 769-778

69. Szczepanik DW, Zak E, Dyduch K, Mrozek J (2014). Chem Phys Lett 583:154-159

70. Szczepanik DW, Andrzejak M, Dominikowska J, Pawełek B, Krygowski TM, Szatyłowicz H, Sola M (2017). PCCP 19: 28970-28981

71. Szczepanik DW, Sola M, Krygowski TM, Szatyłowicz H, Andrzejak M, Pawełek B, Dominikowska J, Kukułka M, Dyduch K (2018). PCCP 20:13430-13436

72. Szczepanik DW, Sola M, Andrzejak M, Pawełek B, Dominikowska J, Kukułka M, Dyduch K (2017). J Comput Chem 38:1640-1656

73. Szatylowicz H, Krygowski TM (2017). Wiadomości Chemiczne $71: 497-516$
74. Hammett LP (1937). J Am Chem Soc 59:96-103

75. Hammett LP (1940) Physical organic chemistry. 1st Ed. Mc GrawHill, New York, p 196

76. Krygowski TM, Wozniak K (1991) In: Zalewski RI, Krygowski TM, Shorter J (eds) Similarity models in organic chemistry, biochemistry and related fields. Similarity models: statistical tools and problems in using them. Chpt. 1. Elsevier, Amsterdam, pp $3-75$

77. Jaffe HH (1953). Chem Rev 53:191-261

78. Hansch C (1969). Acc Chem Res 2:232-239

79. Exner O (1972) In: Chapman NB, Shorter J (eds) Advances in linear free energy relationships. The Hammett equation - the present position, Chpt. 1. Plenum Press, London, p 1

80. Johnson CD (1973) The Hammett equation. Cambridge University Press, Cambridge

81. Shorter J (1991) In: Zalewski RI, Krygowski TM, Shorter J (eds) Similarity models in organic chemistry, biochemistry and related fields. Substituent effect parameters and models applied in organic chemistry. Chpt. 2. Elsevier, Amsterdam, p 77

82. Hansch C, Leo A, Taft RW (1991). Chem Rev 91:165-195

83. Krygowski TM, Stepień BT (2005). Chem Rev 105:3482-3512

84. Exner O, Bohm S (2006). Curr Org Chem 10:763-778

85. Swain CG, Lupton Jr EC (1968). J Am Chem Soc 90:4328-4337

86. Streitwieser Jr A (1961) Molecular orbital theory for organic chemists. Wiley, New York

87. Kemula W, Krygowski TM (1967). Bull Acad Polon Sci Ser Sci Chim 15:479-484

88. Krygowski TM, Tomasik P (1970). Bull Acad Polon Sci Ser Sci Chim 18:303-308

89. Kamieński B, Krygowski TM (1971). Tetrahedron Lett 12:103104

90. Domenicano A, Mazzeo P, Vaciago A (1976). Tetrahedron Lett 17:1029-1032

91. Domenicano A, Murray-Rust P (1979). Tetrahedron Lett 24: 2283-2286

92. Huheey JE (1965). J Phys Chem 69:3284-3291

93. Huheey JE (1966). J Phys Chem 70:2086-2092

94. Campanelli AR, Domenicano A, Ramondo F (2003). J Phys Chem A 107:6429-6440

95. Campanelli AR, Domenicano A, Ramondo F, Hargittai I (2004). J Phys Chem A 108:4940-4948

96. Bachrach SM (2014) Computational organic chemistry. Wiley, New Jersey

97. George P, Trachtman M, Bock CW, Brett AM (1976). J Chem Soc Perkin Trans 2:1222-1227

98. Pross A, Radom L, Taft RW (1980). J Organomet Chem 45:818826

99. Siodla T, Oziminski WP, Hoffmann M, Koroniak H, Krygowski TM (2014). J Organomet Chem 79:7321-7331

100. Gadre SR, Suresh CH (1997). J Organomet Chem 62:2625-2627

101. Galabov B, Ilieva S, Schaefer III HF (2006). J Organomet Chem 71:6382-6387

102. Sadlej-Sosnowska N (2007). J Phys Chem A 111:11134-11,140

103. Galabov B, Ilieva S, Hadijeva B, Atanasov Y, Schaefer III HF (2008). J Phys Chem A 112:6700-6707

104. Sayyed FB, Suresh CH, Gadre SR (2010). J Phys Chem 114: $12330-12,333$

105. Suresh CH, Gadre SR (2008). Phys Chem Chem Phys 10:64926499

106. Remya GS, Suresh CH (2016). Phys Chem Chem Phys 18:2061520,626

107. Sadlej-Sosnowska N (2007). Pol J Chem 81:1123-1134

108. Sadlej-Sosnowska N (2007). Chem Phys Lett 447:192-196

109. Krygowski TM, Sadlej-Sosnowska N (2011). Struct Chem 22:17-22

110. Stasyuk OA, Szatylowicz H, Fonseca Guerra C, Krygowski TM (2015). Struct Chem 26:905-913 
111. Mulliken RS (1955). J Chem Phys 23:1833-1840 1841-1846, 2338-2342, 2343-2346

112. Bader RWM (1990) Atoms in molecules: a quantum theory. Clarendon Press, Oxford

113. Bickelhaupt FM, van der Eikemma NIR, Fonseca Guerra C, Baerends EJ (1996). Organometallics 15:2923-2931

114. Hirshfeld FL (1977). Theor Chim Acta 44:129-138

115. Weinhold F, Landis CR (2005) Valency and bonding, a natural bond orbital donor-acceptor perspective. Cambridge University Press, Cambridge

116. Szatylowicz H, Jezuita A, Ejsmont K, Krygowski TM (2017). Struct Chem 28:1125-1132

117. Szatylowicz H, Jezuita A, Ejsmont K, Krygowski TM (2017). J Phys Chem A 121:5196-5203

118. Shahamirian M, Szatylowicz H, Krygowski TM (2017). Struct Chem 28:1563-1572

119. Varaksin KS, Szatylowicz H, Krygowski TM (2017). J Mol Struct 1137:581-588

120. Szatylowicz H, Siodla T, Stasyuk OA, Krygowski TM (2016). Phys Chem Chem Phys 18:11711-11,721

121. Szatylowicz H, Siodla T, Krygowski TM (2017). J Phys Org Chem 30:e3694

122. Szatylowicz H, Jezuita A, Siodla T, Varaksin KS, Ejsmont K, Shahamirian M, Krygowski TM (2018). Struct Chem 29:1201-1212

123. Szatylowicz H, Jezuita A, Siodla T, Varaksin KS, Ejsmont K, Madura ID, Krygowski TM (2018). J Phys Chem A 122:1896-1904

124. Szatylowicz H, Jezuita A, Siodla T, Varaksin KS, Domanski MA, Ejsmont K, Krygowski TM (2017). ACS Omega 2:7163-7171

125. Hęclik K, Dębska B, Dobrowolski JC (2014). RSC Adv 4:1733717346

126. Hęclik K, Dobrowolski JC (2017). J Phys Org Chem 30:e3656

127. Krygowski TM (1970). Bull Acad Polon Sci Ser Sci Chim 18: 463-468

128. Krygowski TM, Ejsmont K, Stepien MK, Poater J, Sola M (2004). J Organomet Chem 69:6634-6640

129. Minkin VI, Glukhovtsev MN, BYa S (1994) Aromaticity and antiaromaticity, electronic and structural aspect. Wiley, New York

130. Siodla T, Szatylowicz H, Varaksin KS, Krygowski TM (2016). RSC Adv 6:96527-96,530

131. Krygowski TM, Ciesielski A, Cyranski M (1995). Chem Pap 49: 128-132

132. Oziminski WP, Krygowski TM, Fowler PW, Soncini A (2010). Org Lett 12:4880-4883

133. Oziminski WP, Krygowski TM, Noorizadeh S (2012). Struct Chem 23:931-938

134. Krygowski TM, Oziminski WP, Palusiak M, Fowler PW, McKenzie AD (2010). Phys Chem Chem Phys 12:10740-10745

135. Oziminski WP, Krygowski TM (2011). J Mol Model 17:565-572

136. Krygowski TM, Oziminski WP, Cyranski MK (2012). J Mol Model 18:2453-2460

137. Cysewski P, Jelinski T, Krygowski TM, Oziminski WP (2012). Curr Org Chem 16:1920-1933

138. Zborowski K, Alkorta I, Elguero J (2007). Struct Chem 18:797-805

139. Curutcher C, Poater J, Sola M, Elguero J (2011). J Phys Chem A 115:8571-8577

140. Oziminski WP, Krygowski TM (2011). Tetrahedron 67:6316-6321

141. Zborowski KK, Szatyłowicz H, Stasyuk OA, Krygowski TM (2017). Struct Chem 28:1223-1227

142. Mazurek A, JCz D (2013). Org Biomol Chem 11:2997-3013

143. Cyranski MK, Krygowski TM (1995). Pol J Chem 69:1080-1087

144. Cyranski MK, Krygowski TM (1995). Pol J Chem 69:1088-1096
145. Morrison DF (1976) Multivariate statistical methods. McGrawHill Inc, New York

146. Allen FH (2002). Acta Crystallogr Sect B Struct Sci 58:380-388

147. (1989) Cambridge Structural Data Base, User's manuel, part I, II, III, CCDC Cambridge

148. Szatylowicz H, Stasyuk OA, Guerra CF, Krygowski TM (2016). Crystals 6:29

149. Rapaport Z (ed) (2003) The chemistry of phenols. Wiley, New York

150. Krygowski TM, Szatyłowicz H, Zachara JE (2004). J Chem Inf Comput Sci 44:2077-2082

151. Krygowski TM, Zachara JE, Szatyłowicz H (2004). J Org Chem 69:7038-7043

152. Krygowski TM, Szatyłowicz H, Zachara JE (2005). J Chem Inf Model 45:652-456

153. Krygowski TM, Wisiorowski M, Nakata K, Fujio M, Tsuno Y (1996). Bull Chem Soc Jpn 69:2275-2279

154. Krygowski TM, Cyrański M, Nakata K, Fujio M, Tsuno Y (1997). Tetrahedron 53:11383-11,398

155. Krygowski TM (1971). Bull Acad Polon Sci Ser Sci Chim 19:49-59

156. Krygowski TM (1972). Tetrahedron 28:4981-4987

157. Szatyłowicz H, Krygowski TM, Palusiak M, Poater J, Sola M (2011). J Organomet Chem 76:550-556

158. Shahamirian M, Cyrański MK, Krygowski TM (2011). J Phys Chem A 115:12688-12,694

159. Szatylowicz H, Domanski MA, Krygowski TM (2019). ChemistryOpen 8:64-73

160. Zborowski KK, Krygowski TM (2014). Tetrahedron Lett 55: 6359-6361

161. Nekoei AR, Vatanparast M (2019). Phys Chem Chem Phys 21: 623-630

162. Noorizadeh S, Shakerzadeh E (2010). Phys Chem Chem Phys 12: 4742-4749

163. Lloyd D, Marshall DR (1964). Chem Ind (London):1760-1761

164. Collman JP, Moss RA, Goldby SD, Trahanowsky WS (1960). Chem Ind (London):1213-1214

165. Lloyd D, Marshall DR (1971) In: Bergmann ED, Pullman B (eds) Aromaticity, pseudoaromaticity, antiaromaticity. Proceedings of an international symposium held in Jerusalem 1970. Israel Academy of Science and Humanities, Jerusalem, p 85

166. Krygowski TM, Zachara JE (2005). Theor Chem Accounts 114: 229-234

167. Krygowski TM, Zachara JE, Moszyński R (2005). J Chem Inf Model 45:1837-1841

168. Krygowski TM, Stepień BT (2004). Pol J Chem 68:2213-2217

169. Palusiak M, Simon S, Sola M (2006). J Organomet Chem 71: 5241-5248

170. Palusiak M, Simon S, Sola M (2007). Chem Phys 342:43-54

171. Krygowski TM, Bankiewicz B, Czarnecki Z, Palusiak M (2015). Tetrahedron 71:4895-4908

172. Lenain P, Mandado M, Mosquera MA, Bultinck P (2009). J Phys Chem A 112:10689-10696

173. Krygowski TM, Zachara-Horeglad J, Palusiak M (2010). J Organomet Chem 75:4944-4949

174. Krygowski TM, Zachara JE, Osmiałowski B, Gawinecki R (2006). J Organomet Chem 116:7678-7682

175. Raczyńska ED, Krygowski TM, Zachara JE, Ośmiałowski B, Gawinecki R (2005). J Phys Org Chem 18:892-897

Publisher's note Springer Nature remains neutral with regard to jurisdictional claims in published maps and institutional affiliations. 